\title{
Insight into the molecular requirements for pathogenicity of Fusarium oxysporum f. sp. lycopersici through large-scale insertional mutagenesis

\author{
Caroline B Michielse ${ }^{\star *}$, Ringo van Wijk ${ }^{\star \dagger}$, Linda Reijnen*, \\ Ben JC Cornelissen* and Martijn Rep*
}

\begin{abstract}
Addresses: *Plant Pathology, Swammerdam Institute for Life Sciences, University of Amsterdam, Kruislaan 318, 1098 SM Amsterdam, The Netherlands. ${ }^{\dagger}$ Current address: Plant Physiology, Swammerdam Institute for Life Sciences, University of Amsterdam, Kruislaan 318, 1098 SM Amsterdam, The Netherlands.

$\star$ These authors contributed equally to this work.

Correspondence: Caroline B Michielse. Email: c.b.michielse@uva.nl

Published: 9 January 2009

Genome Biology 2009, 10:R4 (doi:10.1 186/gb-2009-10-1-r4)

The electronic version of this article is the complete one and can be found online at http://genomebiology.com/2009//0/I/R4

(C) 2009 Michielse et al.; licensee BioMed Central Ltd.

This is an open access article distributed under the terms of the Creative Commons Attribution License (http://creativecommons.org/licenses/by/2.0), which permits unrestricted use, distribution, and reproduction in any medium, provided the original work is properly cited.

Received: I October 2008

Revised: 22 December 2008

Accepted: 9 January 2009
\end{abstract}

\begin{abstract}
Background: Fusarium oxysporum f. sp. lycopersici is the causal agent of vascular wilt disease in tomato. In order to gain more insight into the molecular processes in $F$. oxysporum necessary for pathogenesis and to uncover the genes involved, we used Agrobacterium-mediated insertional mutagenesis to generate 10,290 transformants and screened the transformants for loss or reduction of pathogenicity.

Results: This led to the identification of 106 pathogenicity mutants. Southern analysis revealed that the average T-DNA insertion is I. 4 and that $66 \%$ of the mutants carry a single T-DNA. Using TAILPCR, chromosomal T-DNA flanking regions were isolated and III potential pathogenicity genes were identified.

Conclusions: Functional categorization of the potential pathogenicity genes indicates that certain cellular processes, such as amino acid and lipid metabolism, cell wall remodeling, protein translocation and protein degradation, seem to be important for full pathogenicity of $F$. oxysporum. Several known pathogenicity genes were identified, such as those encoding chitin synthase $V$, developmental regulator FlbA and phosphomannose isomerase. In addition, complementation and gene knock-out experiments confirmed that a glycosylphosphatidylinositol-anchored protein, thought to be involved in cell wall integrity, a transcriptional regulator, a protein with unknown function and peroxisome biogenesis are required for full pathogenicity of $F$. oxysporum.
\end{abstract}

\section{Background}

Fusarium oxysporum, a soil-borne facultative pathogen with a worldwide distribution, causes vascular wilt and foot-, root-, and bulbrot diseases in a wide variety of economically important crops [1,2]. F. oxysporum isolates are highly host-specific and have been grouped into formae speciales according to 
their host range [1]. Recently, F. oxysporum has also been reported as an emerging human pathogen, causing opportunistic mycoses [3-5].

Over the years numerous studies have been performed to understand $F$. oxysporum-mediated disease development. The process of vascular infection has been studied using light, fluorescence and electron microscopy and can be divided into several steps: root recognition, root surface attachment and colonization, penetration of the root cortex, and hyphal proliferation within the xylem vessels. This hyphal proliferation in vessels causes characteristic disease symptoms, such as vein clearing, leaf epinasty, wilt and defolation, eventually leading to death of the host plant. At this stage, F. oxysporum invades the parenchymatous tissue and starts sporulating on the plant surface, thereby completing its pathogenic life cycle [6].

Forward and reverse genetics have improved our understanding of molecular mechanisms involved in pathogenesis. Targeted deletion of genes encoding a mitogen-activated protein kinase ( $f m k 1$ ) and G-protein subunits $\alpha$ (fga1, fga2) and $\beta$ (fgb1) revealed that mitogen-activated protein kinase (MAPK) and cyclic AMP-protein kinase A (cAMP-PKA) cascades both regulate virulence in $F$. oxysporum [7-11]. In addition, several genes necessary for maintenance of cell wall integrity and full virulence have been identified - encoding chitin synthases (chs2, chs7, chsV, and chsVb), a GTPase (rho1), and a $\beta$-1,3-glucanosyltransferase (gas1) - and it has been postulated that cell wall integrity might be necessary for invasive growth and/or resistance to plant defense compounds [12-16]. The degree to which cell wall degrading enzymes contribute to the infection process is not yet fully understood. It has been described that Fusarium secretes an array of cell wall degrading enzymes, such as polygalacturonases, pectate lyases, xylanases and proteases, during root penetration and colonization [2]. However, inactivation of individual cell wall degrading enzyme- or protease-encoding genes (for example, pectate lyase gene pl1, xylanase genes $x y l_{3}, x y l_{4}$, and $x y l_{5}$, polygalacturonase genes pg1, pg5, and pgx4, and the subtilase gene prt1 [6,17-23]) did not have a detectable effect on virulence. Deletion of $x \ln R$, which encodes the transcriptional activator $X \ln R$, a regulator of the expression of many xylanolytic and cellulolytic genes, had no effect on virulence either, although expression of xylanase genes was strongly reduced [24]. On the other hand, targeted disruption of the carbon catabolite repressor SNF1 did result in reduced expression of several cell wall degrading enzymes and virulence [25], indicating that carbon catabolite repression and, thus, adaptation of the central carbon metabolism plays a role in pathogenicity.

Also, nitrogen regulation was shown to be important for the infection process. Inactivation of the global nitrogen regulator Fnr1 abolished the expression of nutrition genes normally induced during the early phase of infection, and resulted in reduced pathogenicity [26]. Finally, various genes with diverse functions have been identified to play a role in pathogenicity, including those encoding a $\mathrm{pH}$ responsive transcription factor (pacC), a $\mathrm{Zn}(\mathrm{II}) 2 \mathrm{Cys} 6$ transcriptional regulator (FOW2), argininosuccinate lyase ( $A R G 1)$, a mitochondrial carrier protein $\left(F O W_{1}\right)$, an F-box protein ( $\left.F R P 1\right)$, a secreted protein ( $S I X 1)$, a chloride channel (CLC1), and a chloride conductance regulatory protein (FPD1) [27-33].

The majority of the above-mentioned genes have been identified and studied based on the function of homologous genes in other organisms. To uncover genes necessary during pathogenesis in an unbiased manner, insertional mutagenesis has been used for a number of fungal plant pathogens [34,35]. This approach has also been applied to $F$. oxysporum, although only a limited number of insertion mutants were generated using restriction enzyme mediated insertion (REMI) or random plasmid DNA insertion and only a small number of pathogenicity genes have been identified in this way $[13,28-30,32]$.

In order to identify many more genes important for the ability of $F$. oxysporum to cause disease, and thus to gain a more global understanding of the infection process, we used an Agrobacterium-mediated insertional mutagenesis approach. This approach has been successfully used with other plant pathogenic fungi, like Magnaporthe oryzae, M. grisea and Leptosphaeria maculans, to generate large insertional mutant collections and to identify pathogenicity genes [36-38]. In this study, a collection of more than 10,000 transformants of $F$. oxysporum f. sp. lycopersici was generated, and each transformant was tested for loss of pathogenicity. To estimate the probability that a transfer DNA (T-DNA) insertion is linked to the pathogenicity phenotype and since downstream analysis is facilitated by single T-DNA integrations, Southern analysis and thermal asymmetric interlaced PCR (TAIL-PCR) were performed on all pathogenicity mutants. The outcome was used to determine T-DNA copy number and integration patterns and to identify potential pathogenicity genes. Predicted functions of potential pathogenicity genes allowed tentative identification of molecular processes required for pathogenesis. For five genes predicted to be involved in some of these processes, involvement in pathogenicity was verified by complementation and gene knock-out studies.

\section{Results \\ Identification of pathogenicity mutants from a collection of $\boldsymbol{F}$. oxysporum transformants}

A collection of 10,290 transformants was generated through Agrobacterium-mediated transformation using the T-DNA of pPK2hphgfp as insertional mutagen (Figure 1). All transformants were assessed for loss of pathogenicity in root-dip bioassays using three seedlings per transformant. Transformants displaying an apparent loss or strong reduction of pathogenicity were re-tested, again using three seedlings per 
transformant. In this way, out of the 10,290 transformants, 145 putative pathogenicity mutants were identified. Subsequently, these mutants were assessed in a third root-dip bioassay using 20 plants per mutant followed by statistical analysis. This resulted in the identification of 106 mutants with a reproducible pathogenicity defect. The pathogenicity mutants were classified according to severity of pathogenicity loss, based on the average disease index. The average disease index caused by the wild-type parent strain (4287) was $3 \pm$ 0.6 (based on 13 independent bioassays). In total, 20 mutants were classified as non-pathogenic (class 1 , disease index $=0$ ), 47 mutants were severely reduced in pathogenicity (class 2, disease index <1) and 39 mutants were reduced in pathogenicity (class 3 , disease index $\geq 1$, but still statistically different compared to the wild-type infection at a $5 \%$ confidence interval) (Table 1). Thus, $1 \%$ of the entire collection of transformants was (severely) reduced in pathogenicity or totally non-pathogenic on tomato seedlings.

\section{Phenotypic characterization of the pathogenicity mutants}

The growth phenotype on various carbon sources of each pathogenicity mutant was determined to assess whether the reduced pathogenicity phenotype could be attributed to a metabolic defect. All mutants were grown for seven days on potato dextrose agar (PDA), Czapek-Dox agar (CDA) and minimal medium containing as sole carbon source either sucrose, glycerol, ethanol, malic acid or citric acid. Aberrant growth phenotypes among the mutants varied from slightly to severely reduced growth on one or several of the media tested, slightly reduced growth on all media tested, severely reduced growth on all media tested to no growth on any media tested except PDA. In total, 60 of the 106 pathogenicity mutants displayed no aberrant growth phenotype. The frequency and severity of growth phenotypes of the remaining 46 mutants tended to increase with increased reduction of pathogenicity: from the mutant classes 1, 2, and 3, respectively, 60\%, 53\%, and $23 \%$ of the mutants showed a growth phenotype different from the wild-type strain (Table 1). Nevertheless, eight mutants with no detectable growth phenotype still showed complete loss of pathogenicity (class 1).

\section{Analysis of T-DNA integration patterns}

To assess the general characteristics of T-DNA integration into the genome of $F$. oxysporum and to facilitate selection of mutants for further analysis, all mutants were analyzed for TDNA copy number, mode of T-DNA integration (tandem or inverted repeats), abortive T-DNA integration events, and the presence of non-T-DNA (binary vector). In order to discriminate between these various modes of T-DNA integration the chromosomal DNA was cut with BglII, which does not cut within the T-DNA, or BamHI, which cuts once in the T-DNA, and hybridized with five different probes, notably the gpdA, trpC, left border (LB), right border (RB) and binary vector probes (Figure 1a). Examples of various T-DNA integration patterns observed are depicted in Figure 2a-f. In case of a single T-DNA integration, one fragment is observed with either restriction enzyme or probe (Figure 2a, lanes 1 and 2). A double T-DNA integration could result in two integration events at two different chromosomal locations, resulting in two fragments with either restriction enzyme (Figure 2b, lanes 1 and 2). A double T-DNA integration can also occur at one chromosomal location; in this case the T-DNA could be integrated as a tandem repeat, fused at the LB (Figure 2c), or at the RB (Figure 2d). An abortive T-DNA integration event or the presence of non-T-DNA will result in additional fragments in hybridizations using specific border or binary vector probes, respectively (Figure 2e,g lanes 3-5).

Taken together, Southern analysis performed on 99 of the 106 pathogenicity mutants revealed that 65,28 , and 6 of the mutants contained single, double or multiple (three or more) T-DNA insertions, respectively. This translates to an average T-DNA copy number of 1.4. Non-T-DNA was present in $4 \%$ of the pathogenicity mutants. These numbers are comparable to those of the entire transformant collection (a random subset of 72 out of the 10,290 transformants was analyzed in the same way; data not shown). In 22 of the mutants in which a double T-DNA integration had occurred, the two T-DNA copies had integrated in close proximity of each other or exactly at the same chromosomal location, leading to inverted repeats. Only in six mutants with two insertions had the TDNAs integrated in two different chromosomal locations. Finally, based on the results obtained with the LB and RB probes, we concluded that a LB or RB truncation had occurred in $13 \%$ and $1 \%$ of the mutants analyzed, respectively.

Table I

\begin{tabular}{llcc}
\hline \multicolumn{2}{l}{ Classification of pathogenicity phenotypes } & & \\
\hline Class & Pathogenicity phenotype & Number of pathogenicity mutants & Number of growth mutants \\
\hline 1 & Non-pathogenic (DI = 0) & 20 & 12 \\
2 & Severely reduced (DI <I) & 47 & 25 \\
3 & Reduced (DI $\geq 1)$ & 39 & 9 \\
& Total & 106 & 46 \\
\hline
\end{tabular}

DI, disease index. 


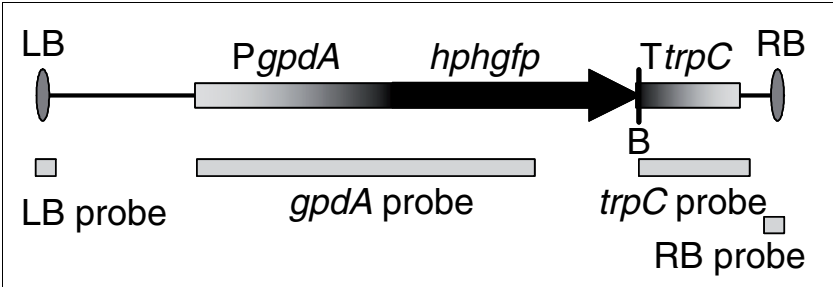

Figure I

T-DNA of pPK2 hphgfp. LB, left border; PgpdA, Aspergillus nidulans glyceraldehyde-3-phosphate dehydrogenase promoter; $h p h g f p$,

translational fusion of hygromycin $B$ resistance gene and green fluorescent protein gene; TtrpC, A. nidulans trpC terminator; $\mathrm{BB}$, right border; $\mathrm{B}$,

BamHI restriction site.

An additional LB or RB was observed in $5 \%$ of the mutants. There was no correlation between severity of pathogenicity loss and the number of T-DNA insertions (data not shown).

In conclusion, the majority of the mutants carried either a single T-DNA or a double T-DNA integrated at a single chromosomal position. In addition, no major differences with regards to the T-DNA copy number and integration pattern were observed between the pathogenicity mutants and a random subset of the entire transformant collection.

\section{Isolation of T-DNA flanking regions}

TAIL-PCR was carried out on all pathogenicity mutants to isolate DNA sequences flanking the T-DNA. Using several different degenerated primers, LB and RB flanking sequences were obtained for, respectively, $74 \%$ and $84 \%$ of the pathogenicity mutants. In total, $89 \mathrm{LB}$ and $109 \mathrm{RB}$ flanking sequences were isolated. From these LB and RB flanking sequences, $20 \%$ and $18 \%$, respectively, corresponded to binary vector backbone or other T-DNA sequences. Another $1 \%$ of the LB and $4 \%$ of the RB flanking sequences were identical to multiple genomic regions, suggesting that the corresponding T-DNAs were integrated into repetitive sequences. Excluding these, in total, 70 unique LB and 85 unique RB flanking sequences were obtained. By comparison to the genome sequence of $F$. oxysporum [39], these unique sequences allowed the localization of the T-DNA integration sites and identification of putative genes affected by these integration events.

\section{Deletions and rearrangements}

Comparison of Southern and TAIL-PCR data enabled us to identify complex T-DNA integration events. For $22 \%$ of the pathogenicity mutants, genomic sequences flanking both the LB and RB were isolated. This revealed that, in most cases, several nucleotides (4-131 bp) were deleted at the insertion site. For four additional mutants, the LB and RB sequences were not located in close proximity of each other in the genome sequence, even though Southern analysis clearly indicated that these mutants carry a single T-DNA. In all four cases the isolated T-DNA flanking regions were located on the same supercontig, but several kilobases apart from each other. For two of these mutants we could confirm by PCR that a region of 4,210 or 9,826 bp was deleted at the insertion site (data not shown), leading to deletion of a complete open reading frame (ORF; FOXG_o8594 and FOXG_1051O, respectively). Chromosomal translocations or inversions were deduced for five pathogenicity mutants. For two mutants such a chromosomal rearrangement (translocation) could be confirmed by PCR. These rearrangements were specific for the mutants, as they were absent in the parental strain (data not shown). Finally, for four of the pathogenicity mutants more T-DNA borders were identified in the TAIL-PCR than was expected based on the Southern analysis. These borders were integrated in close proximity of each other $(<2.5 \mathrm{~kb})$ and their presence could, therefore, have been missed in the Southern analysis due to the choice of restriction enzymes.

\section{Identification of putative pathogenicity genes}

Only when a T-DNA had integrated in an ORF, or within 1,Ooo bp up- or downstream of an ORF, was it assumed that the expression of that gene could be influenced by the T-DNA insertion and the gene was designated as potentially involved in pathogenicity. The T-DNA insertions were grouped based on the distance to the nearest ORF: within an ORF; within 500 bp upstream or 200 bp downstream of an ORF; within 1,000-500 bp upstream or 200-1,00o bp downstream of an ORF; and within 'intergenic regions' (3,000-1,00o bp up- or downstream of an ORF). The majority of the insertions (62) were found in an ORF (Additional data file 1). Of the remaining insertions, 25 (Additional data file 2) were integrated within 500 bp upstream or 200 bp downstream of an ORF and 27 (Additional data file 3) within 1,000-500 bp upstream or 200-1,00o bp downstream of an ORF. A minority of the TDNA insertions (11) was located in intergenic regions (Additional data file 4). Finally, a remaining set of seven T-DNA insertions was integrated at a distance further than 3,000 bp from an ORF and was excluded from further analysis. Based on the F. oxysporum genome map [39], the distribution of the T-DNA integration sites of the pathogenicity mutants was determined and no clustering of the potential pathogenicity genes on the chromosomes was observed (data not shown).

In total, 111 genes potentially involved in pathogenicity were identified (Additional data files 1-3). For most genes, homologues in other fungi were identified; only four putative genes were unique to $F$. oxysporum. Further analysis revealed that in two of these cases a homologue is present in the closely related fungus $F$. verticillioides, which was overlooked in earlier searches due to incorrect annotation of these genes in the F. oxysporum genome. The remaining two are small ORFs (100-170 codons) and at present it is not clear whether these are expressed.

For all putative pathogenicity genes a presumed function for the corresponding protein was deducted based on blast searches in combination with functional assignment accord- 


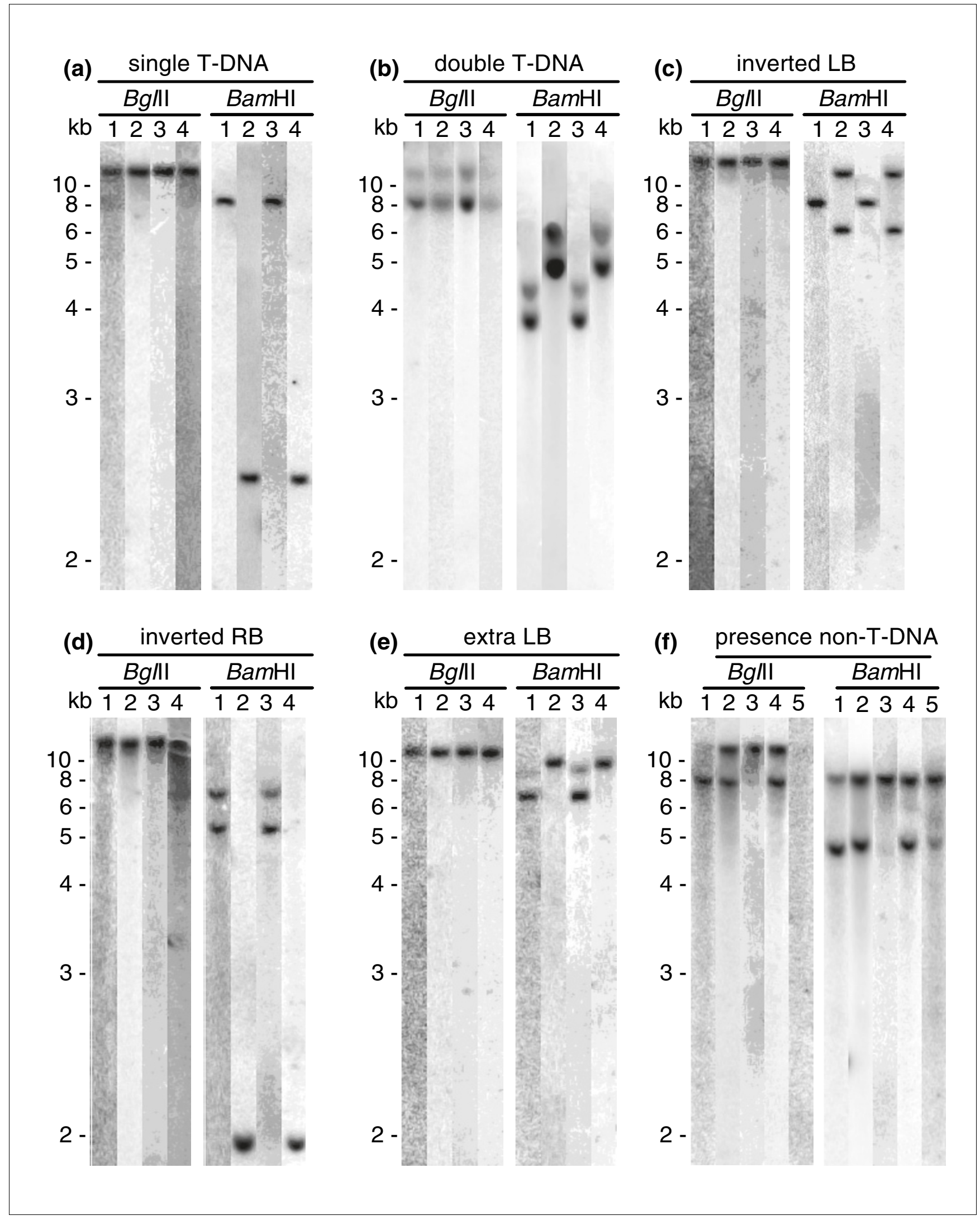

Figure 2 (see legend on next page) 
Figure 2 (see previous page)

T-DNA integration patterns in pathogenicity mutants. (a) Representative transformant with a single T-DNA integration, resulting in one fragment with either restriction enzyme or probe (lanes I and 2). (b) Representative transformant with a double unlinked T-DNA integration, resulting in two fragments with either restriction enzyme or probe (lanes I and 2). (c) Representative transformant with a double inverted T-DNA integration fused at the LB, resulting in one fragment in the Bglll digestion hybridized with the gpdA or trpC probe (Bglll, lanes I and 2), one fragment of $8.4 \mathrm{~kb}$ in the BamHI digestion when hybridized with the gpdA probe $(B a m H I$, lane I) and two fragments when hybridized with the trpC probe (BamHI, lane 2). (d) Representative transformant with a double inverted T-DNA integration fused at the RB, resulting in one fragment in the Bglll digestion when hybridized with the gpdA or trpC probe (Bglll, lanes I and 2), a fragment of $2.2 \mathrm{~kb}$ in the BamHI digestion when hybridized with the $\operatorname{trpC}$ probe (BamHI, lane 2) and two fragments when hybridized with the gpdA probe $(B a m H I$, lane I). (e) Representative transformant with a single T-DNA integration and a second aborted T-DNA integration event. (f) Representative transformant with more than one T-DNA and with binary vector DNA. Blots were hybridized with gpdA (lane I), trpC (lane 2), LB (lane 3), RB (lane 4) and PPZP (lane 5) probes. This figure is a composition of different blots, which results in minor differences in apparent fragment sizes. The negative results for the PPZP probe for the transformants depicted in (b-f) are omitted for clarity.

ing to MIPS [40] (Additional data files 1-3). Examples of identified genes and their possible roles in pathogenesis are listed below.

Three known F. oxysporum pathogenicity genes were identified: the class $\mathrm{V}$ chitin synthase gene chsV, the carbon catabolite derepressing protein kinase gene $S N F 1$, and the $\mathrm{Zn}(\mathrm{II}) 2 \mathrm{Cys} 6$ transcription factor gene FOW2 $[13,25,29]$. The class $\mathrm{V}$ chitin synthase gene and FOW2 were identified more than once (Additional data files 1-3). The reduced or nonpathogenic phenotype of the mutants containing a T-DNA insertion in $S N F 1$ or $C H S V$ correlated well with the published pathogenicity phenotype of the gene disruption/deletion strains $[13,25]$. In contrast to the non-pathogenic phenotype described for the $F$. oxysporum f. sp. melonis FOW2 deletion mutant [29], two independent insertional mutants identified in this study showed a reduced pathogenicity phenotype. This could be due to residual activity of FOW2 in these two mutants due to the location of the T-DNAs, 447 and $690 \mathrm{bp}$ upstream of the FOW2 start codon.

In total, 23 proteins were categorized as having a putative role in primary or secondary metabolism, such as metabolism of amino acids, lipids, vitamin B6 or degradation of aromatic compounds. One of these showed high homology to mannose-6-phosphate isomerase, a protein involved in mannose synthesis and a known pathogenicity factor in Cryptococcus neoformans [41]. Several genes were found with a potential link to degradation of plant material, for example, those encoding L-threo-3-deoxy-hexulosonate aldolase, an enzyme involved in catabolism of D-galacturonate, a principal component of pectin [42], and catechol dioxygenase and 3-carboxy-cis,cis-muconate cyclase, both involved in metabolism of low-molecular weight aromatic compounds, such as protocatechuate and catechol, degradation products of lignin [4346]. Also in this class, succinate-semialdehyde dehydrogenase [NADP ${ }^{+}$, an enzyme involved in the GABA-shunt and found to be up-regulated in $F$. graminearum when grown on hop cell wall [47], was identified as a potential pathogenicity factor. In the categories biogenesis of cellular components, protein fate (folding, modification, destination), and cellular transport, transport facilities and transport routes, several proteins belonging to the same biological process were iden- tified. Genes for four different peroxisome biogenesis proteins (Pex1, Pex10, Pex12, and Pex26) were identified. Peroxisomal metabolism has been shown to be important for pathogenicity of M. grisea and Colletotrichum lagenarium $[48,49]$. Furthermore, three mutants with a T-DNA insertion in a $20 \mathrm{~S} / 26 \mathrm{~S}$ proteasome subunit and three mutants with a TDNA insertion in components of the Sec61 protein translocation complex (SEC61 $\beta, S E C 61 \alpha$, and SEC62) were found, suggesting an important role for protein translocation and degradation in pathogenesis. Three mutants with insertions in or close to genes belonging to the category cell rescue, defense and virulence were identified; these encode a manganese superoxide dismutase (MnSOD), a putative toxin biosynthesis protein and a RTA1 like protein, which confers resistance to aminocholesterols in Saccharomyces cerevisiae [50]. MnSODs have been shown to play a role in pathogenesis in C. neoformans and C. bacillisporus [51,52]. However, deletion of the $\mathrm{MnSOD}$ gene had no effect on pathogenicity of $\mathrm{Col}-$ letotrichum graminicola and Candida albicans [53,54]. The putative toxin biosynthesis protein shows homology to the product of the host-specific AK-toxin gene AKT2 of Alternaria alternata (1E-16, 26\% identity). Deletion of this gene in A. alternata abolished the production of AK-toxin and pathogenicity [55]. In the category development, a gene with homology to the developmental regulator $f l b A$, a regulator of G protein signaling (RGS), was identified. RGS proteins accelerate the rate of GTP hydrolysis by G $\alpha$ proteins and have been shown to play a role in pathogenicity in $C$. neoformans, Cryphonectria parasitica and Metarhizium anisopliae [5658]. Finally, scattered over the remaining categories, genes with roles in ion homeostasis, redox balance, ion/multidrug/ toxin transport and transcriptional regulation were identified. Ion homeostasis (P-type ATPase), redox balance (NADH-ubiquinone oxidoreductase) and major facilitator superfamily (MFS)/ATP-binding cassette (ABC) transporters have been shown to be important for pathogenesis in various fungi [59].

\section{Confirmation of a role of peroxisome and cell wall biogenesis genes in pathogenicity through complementation}

For three pathogenicity mutants a complementation study was performed to assess whether the pathogenicity pheno- 
type was indeed due to the T-DNA insertion. These are pathogenicity mutants $35 \mathrm{~F} 4$ (class 2), 83A1 (class 3) and 51D10 (class 3), which are (severely) reduced in pathogenicity (Additional data file 1). Mutant $35 \mathrm{~F} 4$ contains a single T-DNA insertion in the first exon of FOXG_O2O84, which encodes a protein similar to Peroxin26 (hereafter FoPex26). Reminiscent of other Peroxin26 proteins, which are carboxy-terminally anchored integral peroxisomal membrane proteins [6o], FoPex26 also contains a transmembrane region located near the carboxyl terminus (411-433 amino acids) [61,62]. Mutant 83A1 contains two T-DNAs integrated in close proximity to each other. One RB was isolated using TAIL-PCR and was found to be integrated in the ORF of gene FOXG_o83oo, which encodes a protein similar to Peroxin12 (hereafter FoPex12). Similar to other Peroxin12 proteins, FoPex12 contains a pex2/pex12 amino-terminal region (pfamo4757) and a carboxy-terminal RING finger domain (pfamooo97). Both pex mutants grew normally on rich medium (PDA), but were severely reduced in growth on minimal medium (CDA), possibly due to lack of amino acids and vitamins, and, as expected for peroxisomal biogenesis mutants, on medium containing fatty acids as sole carbon source (Additional data file 5). Mutant 51D10 contains two T-DNA insertions located in close proximity $(2.2 \mathrm{~kb})$ to each other with one T-DNA being truncated. Two RB flanks were isolated with TAIL-PCR. One RB had integrated 801 bp upstream of FOXG_O5O14, which encodes a conserved hypothetical protein. The second RB had integrated into FOXG_O5O13, which encodes a protein with homology to Saccharomyces cerevisiae Dcw1p. FOXG_O5013 is up-regulated in F. oxysporum f. sp. vasinfectum during infection of cotton [63]. Therefore, this gene was selected for complementation of the mutant phenotype. Similar to Dcw1p, the protein encoded by FOXG_o5013 (hereafter FoDcw1) is putatively glycosylphosphatidylinositol (GPI)anchored and belongs to the family of alpha-1,6-mannanases (glycosyl hydrolase family 76, pfamo3663) [61,62]. The pathogenicity mutant displayed no growth abnormalities when grown on various carbon sources.

For FoPex26, FoPex12 and FoDcw1 complementation constructs were generated containing the complete ORF, 6501,00o bp upstream and 500 bp downstream sequences. These complementation constructs were introduced in the corresponding pathogenicity mutants through Agrobacteriummediated transformation and ectopic integration of the complementation construct was verified by PCR (Additional data file 6). For all three pathogenicity mutants, introduction of an intact copy of the corresponding gene restored the disease causing capacity in five independent transformants (Figure 3). Disease index levels of the complementation mutants were comparable to the disease index of the wild-type infection and in all cases significantly different from the disease index of the corresponding pathogenicity mutant (Figure 4). In addition, the reduced growth phenotype of the Peroxin mutants $35 \mathrm{~F} 4$ and $83 \mathrm{~A} 1$ on CDA and fatty acids was complemented in the transformants (Additional data file 5). In conclusion, comple- mentation confirmed that the observed pathogenicity defect in the pathogenicity mutants analyzed was due to the disruption of FOXG_O2O84, FOXG_O83OO and FOXG_O5O13 and that the proteins FoPex26, FoPex12 and FoDcw1 play a crucial role during infection of tomato by $F$. oxysporum.

\section{Gene replacement confirms a role in pathogenesis for two out of four genes analyzed}

To obtain additional information on the link between T-DNA insertions and phenotypes, we decided to perform a gene knock-out study for four potential pathogenicity genes. The first mutant chosen was $18 \mathrm{C}_{4}$ (disease index $<1$ ). This mutant carries a single T-DNA insertion and both the LB and RB were isolated by TAIL-PCR. Analysis revealed that a deletion of seven nucleotides occurred at the insertion point and that the T-DNA was inserted 600 bp upstream of FOXG_o8602. This gene encodes a protein of 242 amino acids, showing homology to spherulin, a protein thought to be involved in tissue desiccation or hydration [64]. The second mutant, 46D7 (disease index approximately 2), carries a single T-DNA with a truncation of the left border. As a result, only the RB was isolated by TAIL-PCR and analysis revealed that it was inserted $18 \mathrm{bp}$ upstream of $F O X G_{-}$o3318. This gene encodes a protein of 586 amino acids with homology to transcriptional regulator Cti6. Like other Cti6 proteins, the protein encoded by FOXG_o3318 (hereafter FoCti6) contains a PHD finger motif (pfamoo628) and a nuclear localization signal (RRRKR at amino acid 68) [61,62]. The third mutant, 54E6 (disease index approximately 1), contains a single T-DNA and, based on the isolated LB and RB in the TAIL-PCR, a 19 nucleotide deletion at the insertion point. The T-DNA was inserted in FOXG_09487, which encodes a hypothetical protein with no known domains. Finally, the fourth mutant chosen, 86A9 (disease index $<1$ ), contains two T-DNAs integrated in close proximity (approximately $600 \mathrm{bp}$ ) of each other. This mutant also contains a chromosomal rearrangement. Three borders were isolated by TAIL-PCR: one RB was inserted 322 bp upstream of FOXG_o9637, and two LBs were inserted $133 \mathrm{bp}$ upstream and into FOXG_o2054, respectively. FOXG_o9637 encodes a hypothetical protein of 387 amino acids with no known domains. FOXG_O2O54 encodes a hypothetical protein of 156 amino acids containing a DUF1183 domain of unknown function (pfamo6682) and an amino-terminal signal peptide (amino acids 1-18) [62]. FOXG_o2054 was chosen as a target for the gene knock out study since it contains a T-DNA insertion in the ORF and is, therefore, the more likely candidate in this mutant.

For all four genes, a gene replacement construct was introduced into the wild-type strain and transformants that had undergone homologous recombination were identified by PCR (Additional data files 7-10). Five independent deletion mutants for each gene were assessed in a root dip bioassay to determine their pathogenicity phenotype. Deletion of FOXG_O8602 and FOXG_O2054 did not have an effect on pathogenicity. The deletion mutants displayed a disease 


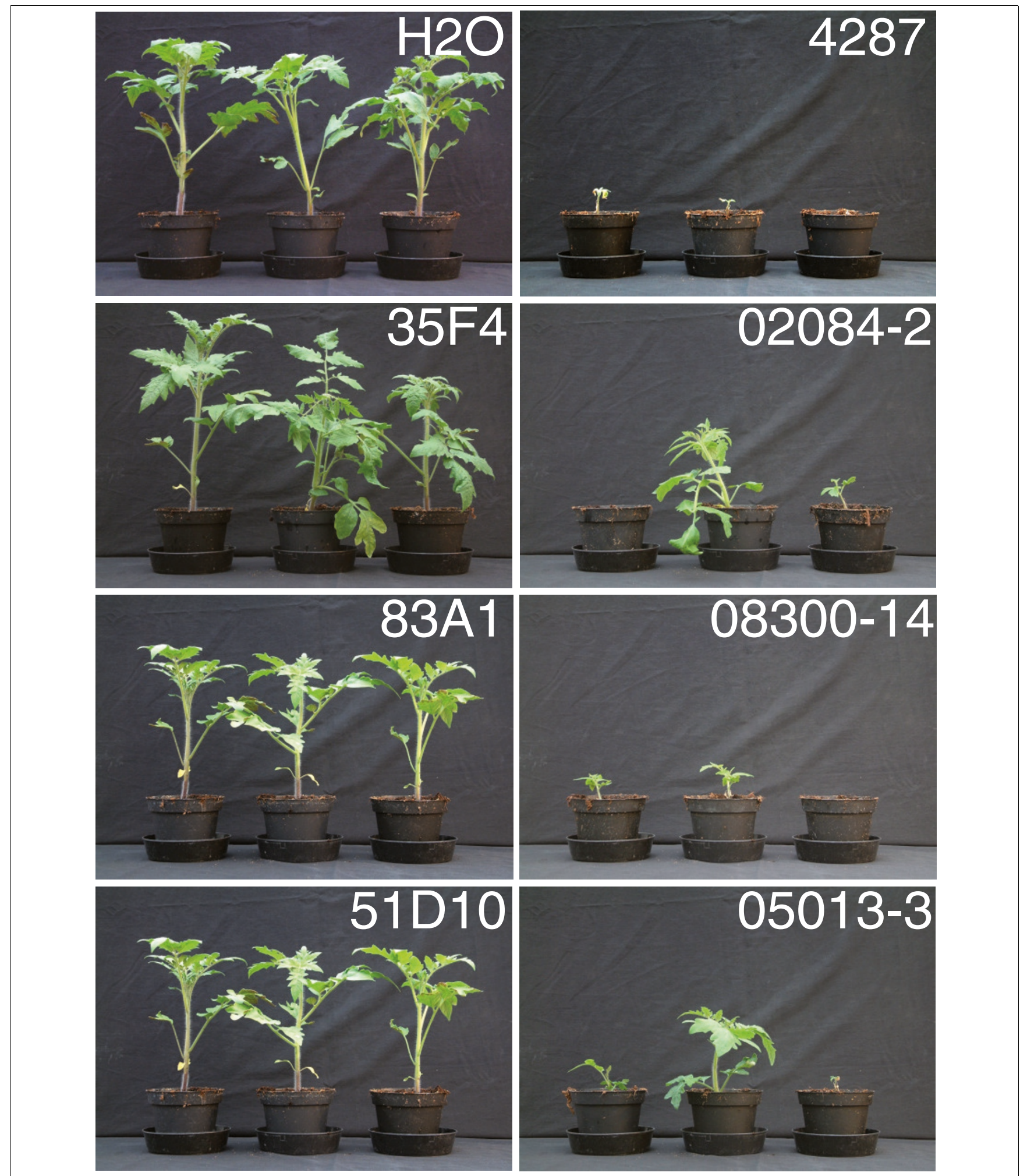

Figure 3

Peroxisomal biogenesis proteins Pex 12 and Pex 26 and cell wall protein Dcw I are necessary for full pathogenicity. Plant phenotypes three weeks after mock inoculation $\left(\mathrm{H}_{2} \mathrm{O}\right)$ or inoculation with $\mathrm{F}$. oxysporum wild type 4287 , pathogenicity mutant $35 \mathrm{~F} 4$, $35 \mathrm{~F} 4$ complementation transformant 02084-2, pathogenicity mutant 83AI, 83AI complementation transformant 08300-I4, pathogenicity mutant 5IDI0, and 5IDI0 complementation transformant 05013-3. 

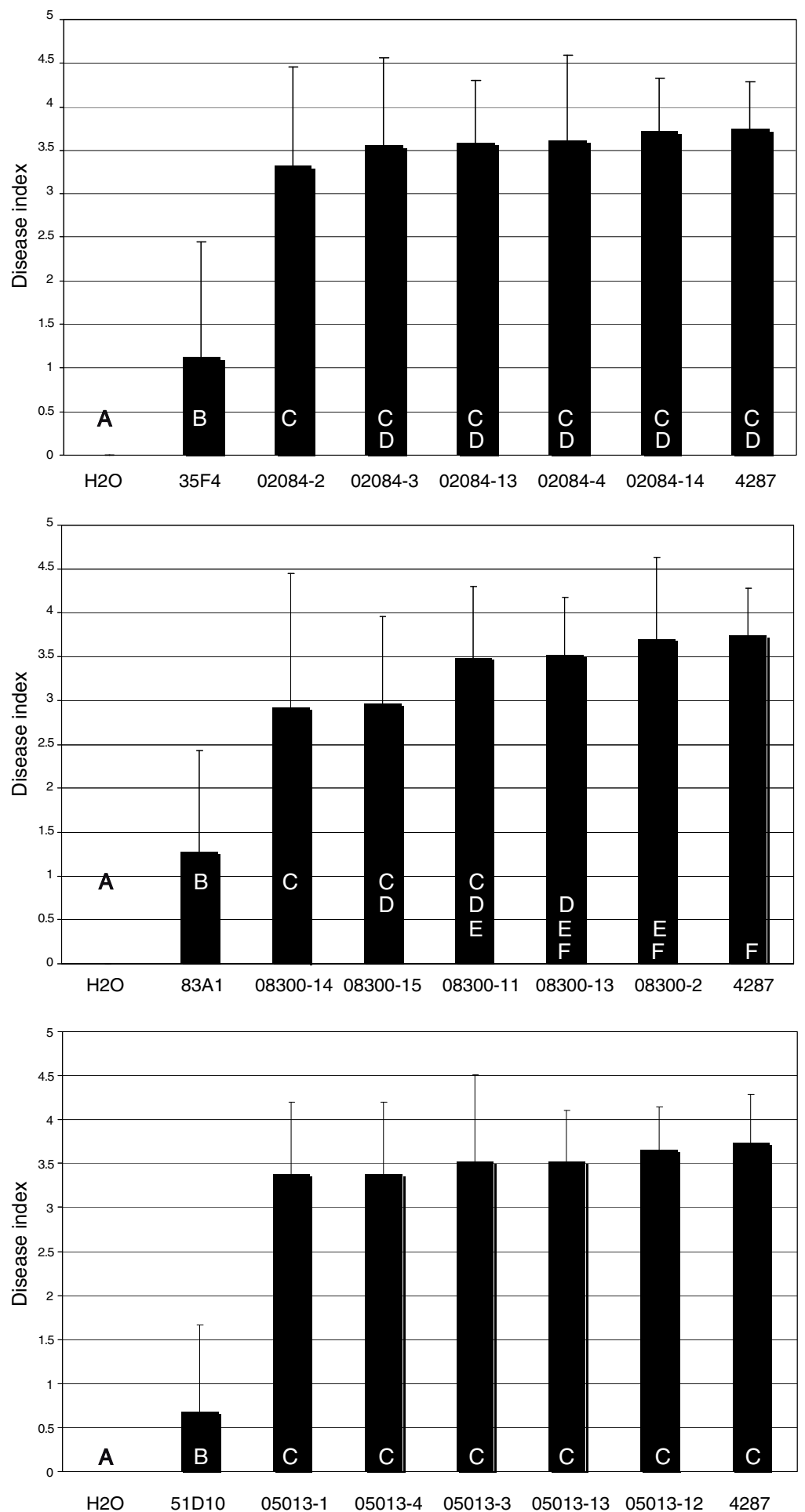

Figure 4

Peroxisomal biogenesis proteins Pex 12 and Pex26 and cell wall protein Dcw I are necessary for full pathogenicity. Average disease index of 20 plants three weeks after mock inoculation $\left(\mathrm{H}_{2} \mathrm{O}\right)$ or inoculation with $F$. oxysporum wild type 4287, pathogenicity mutants $35 \mathrm{~F} 4,83 \mathrm{AI}, 5 \mathrm{IDI} 0$ and their complemented counterparts 02084-2 to $-14,08300-2$ to -15 , and 050I3-I to -13 , respectively. Error bars indicate standard deviation and capital letters define statistically different groups (ANOVA, $p=0.95$ ). 
index that was significantly higher than the corresponding insertional mutagenesis strain and was similar to the disease index obtained with the wild-type strain (Figure $5 \mathrm{a}, \mathrm{c}$ ). In contrast, we were able to confirm a role of $F O X G \_O 3318$ and FOXG_09487 in pathogenicity. Deletion of either of these genes led to reduced pathogenicity (Figure 5b,d). Although the deletion mutants belong to statistically different groups, they were all significantly different from the wild-type strain (Figure 5b,d). Some of the apparent differences in pathogenicity between the different deletion mutants may be due to randomly introduced, minor (epi)genetic differences. However, a mutation or an epigenetic modification in the culture used for transformation influencing our results can be excluded since the cultures we used for transformations were not derived from a single spore but were derived from the same mass of mycelium as the wild type control. Therefore, selection of a random mutation affecting pathogenicity of all transformants but not the wild-type control is essentially excluded. In addition, the reduced phenotype in disease caus- ing ability between the mutants and the wild type is reproducible. In conclusion, two lines of evidence support the notion that the tagged genes are involved in pathogenicity: first, the isolation of the original insertional mutant carrying a mutation in or close to the ORF of this gene; and second, the verification of the pathogenicity phenotype in five gene deletion transformants generated independently. Thus, FoCti6 and hypothetical protein FOXG_o9487 are required for full pathogenicity of $F$. oxysporum towards tomato.

\section{Discussion}

Agrobacterium-mediated transformation is a well established tool for insertional mutagenesis in plants, such as Arabidopsis thaliana and Oryza sativa [65-67]. When it was demonstrated that this transformation system could also be used for the introduction of DNA into yeast and filamentous fungi $[68,69]$, a new possibility for insertional mutagenesis, besides restriction enzyme mediated insertion (REMI) and

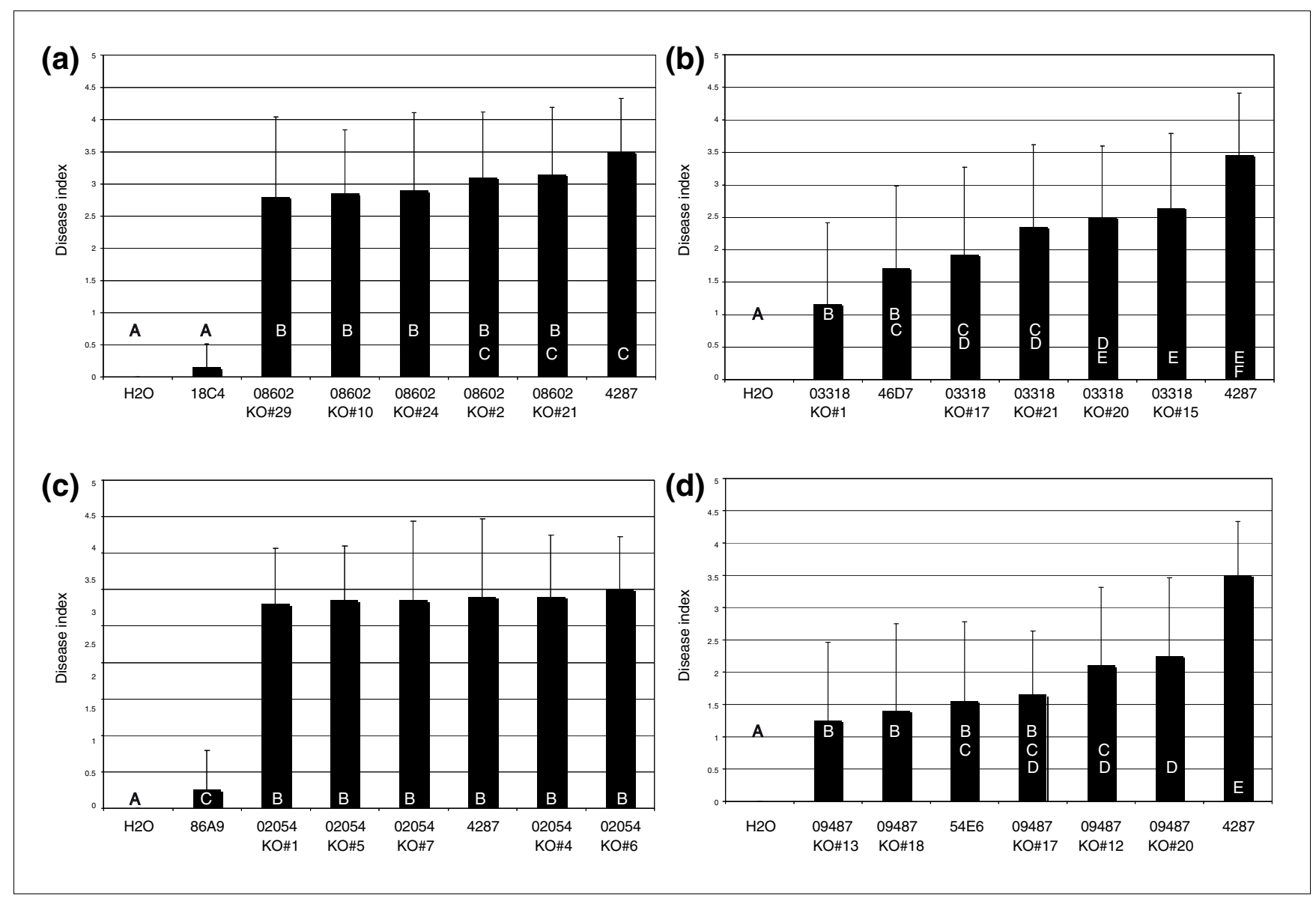

Figure 5

Transcription factor Cti6 and FOXG_09487 are required for full pathogenicity, whereas FOXG_08602 and FOXG_02054 are not. (a-d) Average disease index of 20 plants three weeks after mock inoculation $\left(\mathrm{H}_{2} \mathrm{O}\right)$ or inoculation with $F$. oxysporum wild type 4287, pathogenicity mutant $18 \mathrm{C} 4$ and FOXG_08602 deletion strains KO\#2, I0, 2I, 24, and 29 (a); mutant 46D7 and FOXG_033I 8 deletion strains KO\#I, I5, I7, 20, and 2I (b); mutant 54E6 and FOXG_09487 deletion strains KO\#I2, I3, I7, I8, and 20 (c); and mutant 86A9 and FOXG_02054 deletion strains KO\#I, 4, 5, 6, and 7 (d). Error bars indicate standard deviation and capital letters define statistically different groups (ANOVA, $p=0.95$ ). 
transposon-based methodologies, became available as a tool for large-scale insertional mutagenesis in fungi. Agrobacterium-mediated insertional mutagenesis has since been successfully used to identify pathogenicity factors in several plant-pathogenic fungi [36-38,70,71]. In this study, Agrobacterium-mediated insertional mutagenesis was used to generate pathogenicity mutants of $F$. oxysporum f. sp. lycopersici to identify novel genes required for pathogenesis. In total, 10,290 transformants were generated and assessed for loss of pathogenicity on Solanum lycopersicon (tomato). Out of these, 106 tranformants (1\%) displayed a reproducible nonpathogenic or (severely) reduced pathogenicity phenotype and 111 potential pathogenicity genes were identified. Assuming a genome size of $61 \mathrm{Mb}, 17,735$ genes [39], and random TDNA insertion events, and taking into consideration that several variables are unknown (such as the exact number and length of transcription units, the average distance to an ORF for an insertion to affect gene expression, the number of essential genes and the role of chromatin state (gene activity) on the likelihood of T-DNA insertion), we estimate a genome coverage of $30-40 \%$. Indeed, several confirmed or potential pathogenicity genes were identified more than once, such as those encoding chitin synthase V (three times), developmental regulator FlbA (twice), a hypothetical protein with homology to Ryp1 (three times), carboxy-cis,cis,muconate cyclase (twice) and transcription factor FOW2 (twice), indicating that some redundancy is present in this collection of transformants. However, most known F. oxysporum pathogenicity genes (14 to18 out of the 20 known genes would have been possible to identify in our screen; see Introduction) were not identified in our screen, which underlines the incompleteness of our collection. Our estimations of the average T-DNA copy number, the percentages of single T-DNA integrations, truncations of the LB and RB, non-T-DNA insertions and chromosomal rearrangements and deletions of more than $1 \mathrm{~kb}$ are similar to what has been observed in insertional mutant collections generated with $A$. tumefaciens in other fungi, as well as in plants [36-38,65,67,72-77]. This indicates that the process of T-DNA integration into the genome of $F$. oxysporum is essentially similar to that observed in other organisms. Taken together, we conclude that Agrobacterium-mediated insertional mutagenesis is well suited for creating $F$. oxysporum mutants with desired phenotype(s).

In this study, only when a T-DNA was inserted in an ORF, or within $1 \mathrm{~kb}$ up- or downstream of an ORF, was it assumed that expression of the gene could be influenced by the T-DNA insertion and the gene was marked as a potential pathogenicity gene. This resulted in the identification of 111 potential pathogenicity genes (Additional data files 1-3). Among these, several encode known pathogenicity factors, underscoring the effectiveness of Agrobacterium-mediated insertional mutagenesis to identify pathogenicity factors in $F$. oxysporum. However, from other insertional mutagenesis screens, it is known that not every T-DNA insertion is linked to the mutant phenotype. For C. neoformans and M. grisea the per- centage of tagged mutants ranged from $53 \%$ to $93 \%$ $[38,70,78]$. Therefore, it should be kept in mind that some of the genes identified might not be involved in pathogenicity, as demonstrated by deletion of FOXG_o8602 and FOXG_02054. Nevertheless, functional categorization of the entire list of genes indicated that certain metabolic pathways (amino acid and lipid metabolism), cell wall integrity, and certain cellular processes (protein translocation and degradation) appear to be important for full pathogenicity of $F$. oxysporum. A striking observation was that mutants impaired in primary metabolism or mutants with a severe growth phenotype on CDA (the selective medium) were identified. We hypothesize that although the selection medium does not support auxotrophic growth, these mutants were still able to grow due to the presence of non-transformed fungal hyphae and $A$. tumefaciens cells, which might have served as a nutrient supply. Comparison of our list of potential pathogenicity genes to 672 potential pathogenicity genes published for M. grisea [79] revealed five common (that is, orthologous) genes. Only those T-DNA insertions located within 1,00o bp of an ORF were included in the comparison. The common genes were the known pathogenicity genes for chitin synthase V (chsV), a GTPase activating protein (FOXG_o7699), a RNA polymerase II transcription mediator (FOXG_o8531), a pyridoxine biosynthesis protein involved in vitamin B6 metabolism (FOXG_o8652) and a $\mathrm{Ca}^{2+}$ permease/membrane transporter involved in calcium homeostasis (FOXG_11097). The fact that these genes were found in insertional mutagenesis screens in two plant-pathogenic fungi points strongly towards a conserved requirement of these proteins for colonization of living plants.

The link between T-DNA insertion and pathogenicity phenotype was confirmed for five of seven genes tested either by complementation or gene knock-out. Complementation of two pathogenicity mutants (Pex12 and Pex26) with the corresponding genes completely restored the capacity to cause disease on tomato seedlings, indicating that peroxisomal function is important for pathogenicity of $F$. oxysporum. Peroxisomes are single membrane bound organelles possessing multiple metabolic functions in filamentous fungi, including $\beta$-oxidation of fatty acids, peroxide detoxification and occlusion of septal pores [80-82]. More than 20 peroxin proteins involved in peroxisome biogenesis have been identified in fungi [6o]. Mutations in peroxin genes usually result in the absence of normal peroxisomes, mislocalization of peroxisomal matrix proteins and inability to perform specific biochemical reactions, such as fatty acid catabolism [60]. Four different pex genes, $P E X 1, P E X 1 O, P E X 12$, and PEX26, were identified as potential pathogenicity genes in this study. The four peroxins encoded by these genes are all involved in docking and translocation of receptor-cargo moieties across the peroxisomal membrane $[60,83]$. It can therefore be assumed that inactivation of any one of these peroxins disturbs peroxisomal function, as shown by the reduced growth of these mutants on fatty acids. Peroxisomal function and fatty acid 
metabolism have been shown to play a role during fungal pathogenesis in C. lagenarium, M. grisea, and Ustilago maydis $[38,48,49,84,85]$. Inactivation of PEX6 in C. lagenarium and $M$. grisea resulted in disturbed peroxisomal function, formation of aberrant appressoria, and failure to penetrate the host cuticle $[48,49,85]$. Failure to penetrate the host cuticle was attributed to the aberrant appressoria, which were smaller in size and severely reduced in melanization, and to the absence of appressorium lipolysis $[48,49,85]$. We here show that peroxisomal function is also necessary for pathogenesis of a root infecting fungus that lacks appressoria. It could still be that peroxisomal function is necessary for efficient root penetration. Given the incomplete loss of pathogenicity, the insertion mutants would then penetrate the root cortex at a reduced efficiency. Another possibility is that peroxisomal function is necessary for proper utilization of host nutrients during in planta growth as has been postulated for $U$. maydis [84]. A third possibility is that $F$. oxysporum pex mutants are more sensitive to cytoplasmic leakage during in planta growth due to absence of woronin bodies. Woronin bodies have been identified as a special class of peroxisomes and disruption of peroxisomal function also disturbs the biogenesis of woronin bodies $[80,81,86]$. Combined loss of peroxisomal function and woronin bodies has been observed in a M. grisea PEX6 deletion mutant [49].

Another process that has been shown to be important for pathogenicity of $F$. oxysporum is maintenance of cell wall integrity [12-16]. We also identified genes with a function in cell wall assembly as potential pathogenicity genes, such as those encoding chitin synthase V, mannose-6-phosphate isomerase and a GPI-anchored protein with homology to $S$. cerevisiae Dcw1p. For the first two proteins it was demonstrated earlier that their function is required for pathogenesis and/or for maintaining cell wall integrity in various filamentous fungi $[13,41,87,88]$. We show here that introduction of the $F$. oxysporum DCW1 gene into the dcw1 pathogenicity mutant restores pathogenicity, thereby confirming that FoDcw1 is also necessary for pathogenesis. In $S$. cerevisiae, the absence of Dcw1p leads to defects in bud growth and cell polarity. In addition, an aberrant cell wall with increased chitin content was observed and it was hypothesized that Dcw1p is necessary for normal biogenesis of the cell wall [89,90]. It could be that disturbance of FoDcw1 function in F. oxysporum also leads to a weakened cell wall. This in turn could lead to less efficient penetration of the root cortex, reduced in planta growth and/ or an increased sensitivity to plant defense mechanisms. Alternatively, it could be that an altered cell wall induces host defense responses through exposure or release of molecular patterns that are recognized by the host. The $d c w 1$ mutant was not disturbed in superficial root colonization and was not more sensitive to the cell wall disturbing reagents glucanex and SDS or to high concentrations of sorbitol. However, a minor swelling of the hyphae was observed when the mutant was grown in the presence of calcofluor white (data not shown), indicating that cell wall integrity may be disturbed to some extent in this mutant. Overall, $F_{O D C W}$ is not required for normal development, since no effect on growth on various carbon sources or on sporulation was observed.

Another gene verified here to be important for $F$. oxysporum pathogenicity is FOXG_o9487, which encodes a conserved hypothetical protein. Further studies should be performed to determine what role this protein plays during pathogenicity. Finally, we were able to verify that FoCTI6 is required for full pathogenicity. Its product, FoCti6, is likely involved in transcriptional regulation based on homology to $S$. cerevisiae Cti6. Papamichos-Chronakis et al. [91] studied the role of Cti6 in transcriptional activation and repression in $S$. cerevisiae by using the GAL1 promoter as a model and they showed that Cti6 simultaneously interacts with the transcriptional corepressor complex Cyc8-Tup1 and the co-activator SAGA (Spt-Ada-Gen5-acetytransferase) complex. Co-repressor complex Cyc8-Tup1 controls many physiological pathways, such as glucose repression, hypoxia, and cell type specific expression [92]. The SAGA complex functions as a co-activator complex through histone-post-translational modification and gene regulation [93]. Interestingly, one of the F. oxysporum pathogenicity mutants identified in this study has completely lost FOXG_o8594. The product of this gene shows high homology to one of the components of the SAGA complex, Spt3. This protein has been shown to be required for $C$. albicans virulence and to play opposite roles in filamentous growth in $S$. cerevisiae and C. albicans [94]. We hypothesize that in $F$. oxysporum, certain genes required for pathogenesis are under transcriptional regulation of FoCti6 and possibly the SAGA complex.

\section{Conclusion}

Large scale Agrobacterium-mediated insertional mutagenesis was used successfully to identify novel pathogenicity genes in F. oxysporum. About one in a hundred transformants was reduced in pathogenicity and 111 potential pathogenicity genes were identified. Functional categorization of the potential pathogenicity genes indicate that certain metabolic pathways, cell wall integrity, and a subset of cellular processes seem to be important for full pathogenicity of $F$. oxysporum on tomato. In addition, knock-out and complementation studies confirmed that a GPI-anchored protein thought to be involved in cell wall integrity, a transcriptional regulator, a protein with unknown function and peroxisomal function are required for full pathogenicity. Verification and characterization of additional potential pathogenicity genes is in progress. Together, these efforts should lead to a comprehensive picture of the molecular requirements for pathogenicity of a root-invading fungus. 


\section{Materials and methods}

Strains, plant material, media, culture conditions

F. oxysporum f. sp. lycopersici strain 4287 (race 2), used as the parent strain for fungal transformation, was obtained from A Di Pietro, Universidad de Córdoba, Spain. It was stored as a monoconidial culture at $-80^{\circ} \mathrm{C}$ and revitalized on potato dextrose agar (PDA, Difco, Le Pont de Claix, France) at $25^{\circ} \mathrm{C}$. Agrobacterium tumefaciens EHA105 [95] was used for Agrobacterium-mediated transformation of $F$. oxysporum and was grown in Luria broth medium [96] containing $20 \mu \mathrm{g} /$ $\mathrm{ml}$ rifampicin at $28^{\circ} \mathrm{C}$. Introduction of the plasmids into the Agrobacterium strain was performed as described by Mattanovich et al. [97]. Escherichia coli $\mathrm{DH}_{5}$ alpha (Invitrogen, Breda, The Netherlands) was used for construction, propagation, and amplification of the plasmids and was grown in Luria broth medium at $37^{\circ} \mathrm{C}$ containing either $100 \mu \mathrm{g} / \mathrm{ml}$ ampicillin or $50 \mu \mathrm{g} / \mathrm{ml}$ kanamycin depending on the resistance marker of the plasmid used. Plant line Moneymaker ss590 (Gebr. Eveleens b.v., Aalsmeer, The Netherlands) was used to assess pathogenicity of $F$. oxysporum strains and transformants.

\section{Construction of insertional mutagenesis transformation vector}

The insertional mutagenesis transformation vector pPK2hphgfp contains between the left and right T-DNA border an in-frame fusion of the hygromycin resistance gene with green fluorescent protein (GFP) under the control of the Aspergillus nidulans glyceraldehyde-3-phosphate dehydrogenase $(g p d A)$ promoter and $A$. nidulans $\operatorname{trp} C$ terminator. pPK2hphgfp was constructed in a two-step approach. First, plasmid pPK2 [98] was amplified entirely by PCR using primers HPH-Fwd2-ApaI and HPH-End-ApaI-f (Additional data file 11) in order to introduce an ApaI restriction site before the stop codon of the $h p h$ gene. The pPK2ApaI PCR fragment was digested with ApaI and ligated, resulting in plasmid pPK2hphApaI. The $g f p$ coding sequence was amplified by PCR using primers GFP-f-ApaI and GFP-r-ApaI (Additional data file 11) with plasmid pGPDGFP [99] as a template. The gfp PCR fragment was digested with ApaI and cloned into pPK2hphApaI previously linearized with ApaI, resulting in pPK2hphgfp.

\section{Construction of complementation constructs}

Three complementation constructs containing the ORFs of FOXG_05013, FOXG_o2084, and FOXG_o830o and sequences of several hundred base-pairs up- and downstream of them were constructed. Using pfu polymerase (Fermentas, St. Leon-Rot, Germany) and the primer pairs FOXG_05013fXbaI/FOXG_05013r-AscI, FOXG_02084f-AscI/FOXG_020 84r-XbaI and FOXG_o830of-XbaI/FOXG_o830or-AscI (Additional data file 11), PCR products were generated corresponding to the ORF of FOXG_o5013 together with sequence $740 \mathrm{bp}$ upstream and $500 \mathrm{bp}$ downstream of it, to the ORF of FOXG_O2084 together with sequence 649 bp upstream and $500 \mathrm{bp}$ downstream of it, and to the ORF of FOXG_o830o together with sequence 1,00o bp upstream and 500 bp downstream of it, respectively. The PCR products were cloned into pGEM-T Easy (Promega, Leiden, The Netherlands) and sequenced on an ABI PRISM genetic analyzer using an ABI PRISM BigDye Terminator kit (Applied Biosystems, Nieuwekerk a/d IJssel, The Netherlands) and the corresponding FOXG primers listed in Additional data file 11. Subsequently, pGEMtFOXG_02084,pGEMtFOXG_05013 and pGEMtFOX G_o830o were digested with $X b a I$ and $A s c I$ and the FOXG $X \overline{b a I} / A s c \mathrm{I}$ fragments were cloned into $X b a \mathrm{I} / A s c \mathrm{I}$-digested pRW1p [100], resulting in pRW1pFOXG_02084, pRW1pFOXG_05013 and pRW1pFOXG_o830o, respectively.

\section{Construction of gene disruption constructs}

Gene disruption constructs containing a hygromycin resistance cassette and sequences of $F O X G \_08602, F O X G \_03318$, FOXG_09487 and FOXG_o2054 including several basepairs upstream and downstream of them were generated. PCR products corresponding to the upstream and downstream sequences were generated using $p f u$ polymerase (Fermentas) and the primer pairs FOXG_o8602-f3/ FOXG_08602-r3 and FOXG_o8602-f4/FOXG_08602-r4, FOXG_03318-f1/FOXG_03318-r1 and FOXG_03318-f2/ FOXG_03318-r2, FOXG_09487-f1/FOXG_09487-r1 and FOXG_09487-f2/FOXG_09487-r2 and 86A9pro_fw/ 86A9pro_rev and 86A9term_fw/86A9term_rev (Additional data file 11). The PCR products were cloned into pGEM-T Easy (Promega) and sequenced on an ABI PRISM genetic analyzer using ABI PRISM BigDye Terminator kit (Applied Biosystems), using M13forward and M13reverse primers for sequencing. Subsequently, an AscI/HindIII- or KpnI/PacIdigested fragment corresponding to the FOXG_o8602 promoter and terminator region, a KpnI/PacI- or HindIII/XbaIdigested fragment corresponding to the FOXG_o3318 terminator or promoter region, a KpnI/PacI- or HindIII/XbaIdigested fragment corresponding to the FOXG_o9487 terminator or promoter region, or a KpnI/PacI- or AscI/XbaIdigested fragment corresponding to the $F O X G \_02054$ terminator or promoter region were sequentially cloned in $\mathrm{pRW} 2 \mathrm{~h}$ [100], resulting in pRW2hFOXG_o8602KO, pRW2hFOXG_ 03318KO,pRW2hFOXG_09487KO or pRW2hFOXG_02054 $\mathrm{KO}$, respectively.

\section{Fungal transformation, pathogenicity and growth assays} Agrobacterium-mediated transformation of $F$. oxysporum $\mathrm{f}$. sp. lycopersici was performed as described by Mullins et al. [101] with minor adjustments [102]. Depending on the selection marker used, transformants were selected on Czapek Dox agar (CDA, Oxoid, Basingstoke, Hampshire, England) containing $100 \mu \mathrm{g} / \mathrm{ml}$ Hygromycin (Duchefa, Haarlem, The Netherlands) or on CDA containing o.1 M TrisHCl pH 8 and $100 \mu \mathrm{g} / \mathrm{ml}$ Zeocin (InvivoGen, Toulouse, France). 
Plant infection was performed using 9- to 11-day-old seedlings (Moneymaker ss590) and following the root-dip inoculation method [103]. For the high throughput three-plantsin-one-pot bioassays, the inoculum was prepared by growing the independent $F$. oxysporum transformants on PDA medium for 5 to 6 days followed by collection of microconidia using $5 \mathrm{ml}$ of sterilized water. The conidial suspensions were collected in 24-well plates (one transformant per well) and in each well three uprooted tomato seedlings were incubated for about one minute. Subsequently, the three seedlings were planted in one container (12 cm in diameter) containing potting soil. After three weeks the degree of infection was determined by visual inspection.

For the standard bioassay the inoculum was prepared by growing $F$. oxysporum for 5 days in $\mathrm{NO}_{3}$ medium (0.15\% Yeast Nitrogen Base, $3 \%$ sucrose, $100 \mathrm{mM} \mathrm{KNO}_{3}$ ) at $25^{\circ} \mathrm{C}$ and shaking at $150 \mathrm{rpm}$. Cultures were then filtered through one layer of Miracloth (Calbiochem, Darmstadt, Germany), centrifuged and washed with sterile water, and adjusted to a concentration of $10^{7}$ conidia/ml. The uprooted seedlings (20 per fungal strain) were incubated for about one minute in the conidial suspension and individually planted in a container (12 cm in diameter) containing potting soil. The inoculated plants were grown in a random block design (five replicates per block). After three weeks, the degree of vascular browning and the weight above the cotyledons were determined for each plant. Disease index was scored on a scale from o to 4 (o, healthy plant; 1 , slightly swollen hypocotyl; 2, one brown vascular bundle in hypocotyl; 3 , two or three brown vascular bundles and/or severe growth distortion (small plant and/or asymmetric development); 4, more than three brown vascular bundles and/or very small wilted plant or dead). Statistical analysis (ANOVA and Fisher post hoc test) was performed using StatView ${ }^{\mathrm{TM}} \mathrm{SE}+\mathrm{v} 1.03$.

All transformants tested in the standard bioassay were also subjected to growth tests. For this purpose $2 \mu$ of the conidial suspension (107 conidia/ml) was spotted on CDA, PDA, and minimal medium (0.17\% Yeast Nitrogen Base, 50 mM $\mathrm{KNO}_{3}$ and $1.5 \%$ bacto agar (Difco)) supplemented either with $1 \%$ ethanol, glycerol, malic acid $\mathrm{pH}$ 6.0, citric acid $\mathrm{pH}$ 6.o, sucrose or no carbon source. After an incubation period of 7 days at $25^{\circ} \mathrm{C}$ the transformants were scored based on colony diameter and growth phenotype in comparison to the wild type strain. The growth assay of the pex mutants on minimal medium containing 1\% Tween2o, oleic acid or olive oil was performed as described above.

\section{Isolation of T-DNA flanking regions}

TAIL-PCR was used to isolate genomic DNA flanking the inserted T-DNA from those transformants that were significantly reduced in pathogenicity. The TAIL-PCR conditions were adapted from the protocol described by Mullins et al. [101] and are described in Additional data file 12. The primers for isolating the RB flanking regions and arbitrary degenerate primer AD1 were described by Mullins et al. [101]. Primers used for isolating the LB flanking regions and additional degenerate primers used in this study are listed in Additional data file 11. Depending on the degenerate primer used, the final concentration of the primers in the TAIL-PCR were 0.4 $\mu \mathrm{M}$ specific primer and $4 \mu \mathrm{M}$ degenerate primer for $\mathrm{AD} 1$ or $\mathrm{AD} 4$ or $0.2 \mu \mathrm{M}$ specific primer and $1.5 \mu \mathrm{M}$ degenerate primer for $\mathrm{AD} 2, \mathrm{AD}_{3}, \mathrm{AD} 6, \mathrm{AD} 7$, or $\mathrm{AD} 8$. The tertiary TAIL-PCR product(s) of each transformant was/were purified using Qiaquick columns (Qiagen, Hilden, Germany) and ligated into pGEM-T Easy (Promega). Colony PCR was used to identify the correct clones using primers M13forward and M13reverse (Additional data file 11). The PCR products from the colony PCR were sequenced on an ABI PRISM genetic analyzer using ABI PRISM BigDye Terminator kit (Applied Biosystems) and M13forward and M13reverse as sequence primers. After in silico removal of T-DNA border sequences, the sequences of the TAIL-PCR product were used to search for nucleotide and amino acid similarities by BLASTN and BLASTX algorithms, respectively, against the Fusarium group genome database [39] and NCBI [104].

\section{Molecular analysis of the transformants}

F. oxysporum was grown in $50 \mathrm{ml} \mathrm{NH}_{4}$ medium (0.17\% Yeast Nitrogen Base, $3 \%$ sucrose, $50 \mathrm{mM}\left(\mathrm{NH}_{4}\right)_{2} \mathrm{SO}_{4}$ ) for 5 days at $25^{\circ} \mathrm{C}$ shaking at $175 \mathrm{rpm}$. Mycelium was harvested by filtration through Miracloth, washed with deionized water and freeze-dried overnight. Genomic DNA was isolated as described by Kolar et al. [105] with minor adjustments. Briefly, 2 ml DNA-extraction buffer (0.2 M TrisHCL pH 8.5, 0.25 M NaCl, o.05 M EDTA pH 8.0, $48 \mathrm{mg} / \mathrm{ml}$ sodium 4-aminosalicylate dihydrate (PAS, Sigma-Aldrich, Zwijndrecht, The Netherlands), $8 \mathrm{mg} / \mathrm{ml}$ Triisopropylnaphthalenesulfonic acid sodium (TIPS, Sigma-Aldrich) and $2 \mathrm{ml}$ water-saturated phenol-chloroform (1:1) was added to ground mycelium, mixed and centrifuged for 30 minutes at 3,500 rpm and $4^{\circ} \mathrm{C}$. DNA was precipitated from the aqueous phase with 0.7 volume isopropanol and 0.1 volume $4 \mathrm{M} \mathrm{NaCl}$ and centrifugation for 30 minutes at $3,500 \mathrm{rpm}$ and $4^{\circ} \mathrm{C}$. The pellet was resuspended in $400 \mu \mathrm{lE}$ buffer (10 mM TrisHCL pH7.5, $1 \mathrm{mM}$ EDTA pH 8.0) and extracted three times with water-saturated phenol:chloroform (1:1). DNA was then precipitated with 2 volumes $96 \%$ ethanol and 0.1 volume $3 \mathrm{M}$ NaAc. The DNA was finally dissolved in $100 \mu \mathrm{l}$ deionized water.

For Southern analysis, $10 \mu \mathrm{g}$ genomic DNA of each transformant was digested with $20 \mathrm{U}$ BglII or $20 \mathrm{U}$ BamHI overnight at $37^{\circ} \mathrm{C}$. The samples were loaded on a $1 \% 0.5 \times$ Trisborate/EDTA gel and run for $18 \mathrm{~h}$ at $45 \mathrm{~V}$. The digested DNA was transferred to Hybond-N+ (Amersham Pharmacia, Diegem, Belgium) as described by Sambrook et al. [96]. The probes used for Southern analysis were a 1,744 bp NheI-NcoI and a 780 bp BamHI-HindIII fragment of plasmid pPK2hphgfp corresponding to the $g p d A$ promoter and a part of the hygromycin resistance gene $(h p h)$ and $\operatorname{tr} p C$ terminator, respectively. Plasmid pPZP201BK [106] was used for detec- 
tion of the binary backbone. For the detection of the left and right T-DNA border $381 \mathrm{bp}$ and $327 \mathrm{bp}$ PCR products were generated using primers LB-f and pPK2-LB1 and primers pPK2-RB1 and RB-r, respectively [101] (Additional data file 11). The plasmid pPK2hphgfp was used as template DNA for this PCR. The DecaLabel ${ }^{\mathrm{TM}}$ DNA Labeling Kit (Fermentas) was used to label probes with $[\alpha-32 \mathrm{P}] \mathrm{dATP}$. Hybridization was done overnight at $65^{\circ} \mathrm{C}$ in $0.5 \mathrm{M}$ sodium phosphate buffer, pH 7.2, containing 7\% SDS and $1 \mathrm{mM}$ EDTA. Blots were washed with $0.2 \times$ SSC, $0.1 \%$ SDS. Hybridization signals were visualized by phosphorimaging (Molecular Dynamics, Diegem, Belgium).

\section{Abbreviations}

CDA: Czapek-Dox agar; GFP: green fluorescent protein; GPI: glycosylphosphatidylinositol; LB: left border; ORF: open reading frame; PDA: potato dextrose agar; RB: right border; TAIL-PCR: thermal asymmetric interlaced PCR; T-DNA: transfer DNA.

\section{Authors' contributions}

MR and CM designed the study; CM, RvW and LR carried out the experiments and performed data processing; CM interpreted the data and wrote the manuscript; BC provided guidance and review.

\section{Additional data files}

The following additional data are available with the online version of this paper. Additional data file 1 is a table listing pathogenicity mutants with a T-DNA insertion in an ORF. Additional data file 2 is a table listing pathogenicity mutants with a T-DNA insertion within 500 bp up- or 200 bp downstream of an ORF. Additional data file 3 is a table listing pathogenicity mutants with a T-DNA insertion within 1,000-500 bp up- or 200-1,00o bp downstream of an ORF. Additional data file 4 is a table listing pathogenicity mutants with a TDNA insertion in an 'intergenic' region (defined as 3,00o1,00o bp up- or downstream of an ORF). Additional data file 5 is a figure showing that the growth of the pex mutants is disturbed on minimal medium and fatty acids. Additional data file 6 is a figure depicting the method and analysis of transformants complemented with FOXG_o2084, FOXG_o83Oo or FOXG_05013.

Additional data file 7 is a figure depicting the method and analysis of transformants deleted for FOXG_o8602. Additional data file 8 is a figure depicting the method and analysis of transformants deleted for FOXG_o3318. Additional data file 9 is a figure depicting the method and analysis of transformants deleted for FOXG_o9487.

Additional data file 10 is a figure depicting the method and analysis of transformants deleted for FOXG_O2O54. Addi- tional data file $\mathbf{1 1 1 1}$ is a table listing primer sequences used for PCR and sequencing. Additional data file 12 is a table listing the conditions used for TAIL-PCR.

\section{Acknowledgements}

The authors would like to thank Antonio Di Pietro for providing F. oxysporum strain 4287, Sarah Covert for the vector pPK2, LiJun Ma for mapping the potential pathogenicity genes on the $F$. oxysporum physical map and Birgitt Oeser for computational support for the comparison of the M. grisea and $F$. oxysporum potential pathogenicity genes. Furthermore, we would like to thank Harold Lemereis, Thijs Hendrix, and Ludek Tikovsky for managing the plant growth facilities and their assistance with bioassays. Most of this research was funded by the Utopa Foundation.

\section{References}

I. Armstrong GM, Armstrong JK: Formae speciales and races of Fusarium oxysporum and Alternaria alternata. In Fusarium: Diseases, Biology and Taxonomy Edited by: Cook R. University Park, PA: Penn State University Press; 1981:391-399.

2. Beckman CH: The Nature of Wilt Diseases of Plants St Paul, MN: American Phytopathology Society; 1987.

3. Albisetti M, Lauener RP, Gungor T, Schar G, Niggli FK, Nadal D: Disseminated Fusarium oxysporum infection in hemophagocytic lymphohistiocytosis. Infection 2004, 32:364-366.

4. Anaissie EJ, Kuchar RT, Rex JH, Francesconi A, Kasai M, Muller FM, Lozano-Chiu M, Summerbell RC, Dignani MC, Chanock SJ, Walsh TJ: Fusariosis associated with pathogenic Fusarium species colonization of a hospital water system: a new paradigm for the epidemiology of opportunistic mold infections. Clin Infect Dis 2001, 33:187|-1878.

5. Romano C, Miracco C, Difonzo EM: Skin and nail infections due to Fusarium oxysporum in Tuscany, Italy. Mycoses 1998, 41:433-437.

6. Di Pietro A, Madrid MP, Caracuel Z, Delgado-Jarana J, Roncero MI: Fusarium oxysporum: exploring the molecular arsenal of a vascular wilt fungus. Mol Plant Pathol 2003, 4:3| 5-325.

7. Delgado-Jarana J, Martinez-Rocha AL, Roldan-Rodriguez R, Roncero MI, Di Pietro A: Fusarium oxysporum G-protein beta subunit Fgb I regulates hyphal growth, development, and virulence through multiple signalling pathways. Fungal Genet Biol 2005, 42:61-72.

8. Di Pietro A, Garcia-MacEira FI, Meglecz E, Roncero MI: A MAP kinase of the vascular wilt fungus Fusarium oxysporum is essential for root penetration and pathogenesis. Mol Microbiol 2001, 39: I |40-II52.

9. Jain S, Akiyama K, Kan T, Ohguchi T, Takata R: The G protein beta subunit FGBI regulates development and pathogenicity in Fusarium oxysporum. Curr Genet 2003, 43:79-86.

10. Jain S, Akiyama K, Mae K, Ohguchi T, Takata R: Targeted disruption of a $\mathbf{G}$ protein alpha subunit gene results in reduced pathogenicity in Fusarium oxysporum. Curr Genet 2002, 4I:407-4I3.

II. Jain S, Akiyama K, Takata R, Ohguchi T: Signaling via the G protein alpha subunit $F G A 2$ is necessary for pathogenesis in Fusarium oxysporum. FEMS Microbiol Lett 2005, 243:I65-I72.

12. Caracuel Z, Martinez-Rocha AL, Di Pietro A, Madrid MP, Roncero MI: Fusarium oxysporum gas I encodes a putative beta-I,3-glucanosyltransferase required for virulence on tomato plants. Mol Plant Microbe Interact 2005, I 8: I | 40- I | 47.

13. Madrid MP, Di Pietro A, Roncero MI: Class V chitin synthase determines pathogenesis in the vascular wilt fungus Fusarium oxysporum and mediates resistance to plant defence compounds. Mol Microbiol 2003, 47:257-266.

14. Martinez-Rocha AL, Roncero MI, Lopez-Ramirez A, Marine M, Guarro J, Martinez-Cadena G, Di Pietro A: Rhol has distinct functions in morphogenesis, cell wall biosynthesis and virulence of Fusarium oxysporum. Cell Microbiol 2008, I 0: | 339- I 35I.

15. Martin-Udiroz M, Madrid MP, Roncero MI: Role of chitin synthase genes in Fusarium oxysporum. Microbiology 2004, I 50:3175-3187.

16. Martin-Urdiroz M, Roncero MI, Gonzalez-Reyes JA, Ruiz-Roldan C: ChsVb, a class VII chitin synthase involved in septation, is critical for pathogenicity in Fusarium oxysporum. Eukaryot Cell 
2008, 7:||2-|2|

17. Di Pietro A, Garcia Maceira FI, Meglecz E, Roncero MIG: Endopolygalacturonase PGI in different formae speciales of Fusarium oxysporum. Appl Environ Microbiol 1998, 64:1967-1971.

18. Di Pietro A, Huertas-Gonzalez MD, Gutierrez-Corona JF, MartinezCadena G, Meglecz E, Roncero MIG: Molecular characterization of a subtilase from the vascular wilt fungus Fusarium oxysporum. Mol Plant Microbe Interact 200I, I 4:653-662.

19. Garcia-Maceira FI, Di Pietro A, Huertas-Gonzalez MD, Ruiz-Roldan $\mathrm{MC}$, Roncero MI: Molecular characterization of an endopolygalacturonase from Fusarium oxysporum expressed during early stages of infection. Appl Environ Microbiol 200I, 67:2191-2196.

20. Garcia-Maceira FI, Di Pietro A, Roncero MI: Cloning and disruption of pgx4 encoding an in planta expressed exopolygalacturonase from Fusarium oxysporum. Mol Plant Microbe Interact 2000, | 3:359-365.

21. Gomez-Gomez E, Isabel M, Roncero G, Di Pietro A, Hera C: Molecular characterization of a novel endo-beta-I,4-xylanase gene from the vascular wilt fungus Fusarium oxysporum. Curr Genet 200I, 40:268-275.

22. Gomez-Gomez E, Ruiz-Roldan MC, Di Pietro A, Roncero MI, Hera C: Role in pathogenesis of two endo-beta-I,4-xylanase genes from the vascular wilt fungus Fusarium oxysporum. Fungal Genet Biol 2002, 35:21 3-222.

23. Huertas-Gonzalez MD, Ruiz-Roldan MC, Garcia Maceira FI, Roncero MI, Di Pietro A: Cloning and characterization of pll encoding an in planta-secreted pectate lyase of Fusarium oxysporum. Curr Genet 1999, 35:36-40.

24. Calero-Nieto F, Di Pietro A, Roncero MI, Hera C: Role of the transcriptional activator $x \ln R$ of Fusarium oxysporum in regulation of xylanase genes and virulence. Mol Plant Microbe Interact 2007, 20:977-985

25. Ospina-Giraldo MD, Mullins E, Kang S: Loss of function of the Fusarium oxysporum SNFI gene reduces virulence on cabbage and Arabidopsis. Curr Genet 2003, 44:49-57.

26. Divon HH, Ziv C, Davydov O, Yarden O, Fluhr R: The global nitrogen regulator, FNRI, regulates fungal nutrition-genes and fitness during Fusarium oxysporum pathogenesis. Mol Plant Pathol 2006, 7:485-497.

27. Canero DC, Roncero MI: Influence of the chloride channel of Fusarium oxysporum on extracellular laccase activity and virulence on tomato plants. Microbiology 2008, I 54:|474-|48|

28. Duyvesteijn RG, van Wijk R, Boer Y, Rep M, Cornelissen BJ, Haring MA: Frpl is a Fusarium oxysporum F-box protein required for pathogenicity on tomato. Mol Microbiol 2005, 57:105I-I063.

29. Imazaki I, Kurahashi M, lida Y, Tsuge T: Fow2, a Zn(II)2Cys6-type transcription regulator, controls plant infection of the vascular wilt fungus Fusarium oxysporum. Mol Microbiol 2007, 63:737-753.

30. Inoue I, Namiki F, Tsuge T: Plant colonization by the vascular wilt fungus Fusarium oxysporum requires FOWI, a gene encoding a mitochondrial protein. Plant Cell 2002, | 4:|869-|883.

31. Kawabe M, Mizutani K, Yoshida T, Teraoka T, Yoneyama K, Yamaguchi I, Arie T: Cloning of the pathogenicity-related gene FPDI in Fusarium oxysporum f. sp. lycopersici. J General Plant Pathol 2004, 70:16-20

32. Namiki F, Matsunaga M, Okuda M, Inoue I, Nishi K, Fujita Y, Tsuge T: Mutation of an arginine biosynthesis gene causes reduced pathogenicity in Fusarium oxysporum f.sp. melonis. Mol Plant Microbe Interact 2001, 14:580-584.

33. Rep M, Does HC van der, Meijer M, van Wijk R, Houterman PM, Dekker HL, de Koster CG, Cornelissen BJ: A small, cysteine-rich protein secreted by Fusarium oxysporum during colonization of xylem vessels is required for $1-3-$-mediated resistance in tomato. Mol Microbiol 2004, 53:|373-| 383.

34. Maier FJ, Schafer W: Mutagenesis via insertional- or restriction enzyme-mediated-integration (REMI) as a tool to tag pathogenicity related genes in plant pathogenic fungi. Biol Chem 1999, 380:855-864.

35. Mullins ED, Kang S: Transformation: a tool for studying fungal pathogens of plants. Cell Mol Life Sci 200I, 58:2043-2052.

36. Betts MF, Tucker SL, Galadima N, Meng Y, Patel G, Li L, Donofrio N, Floyd A, Nolin S, Brown D, Mandel MA, Mitchell TK, Xu JR, Dean RA, Farman ML, Orbach MJ: Development of a high throughput transformation system for insertional mutagenesis in Magnaporthe oryzae. Fungal Genet Biol 2007, 44:1035-1049.
37. Blaise F, Remy E, Meyer M, Zhou L, Narcy JP, Roux J, Balesdent MH, Rouxel T: A critical assessment of Agrobacterium tumefaciensmediated transformation as a tool for pathogenicity gene discovery in the phytopathogenic fungus Leptosphaeria maculans. Fungal Genet Biol 2007, 44:I23-I38.

38. Jeon J, Park SY, Chi MH, Choi J, Park J, Rho HS, Kim S, Goh J, Yoo S, Choi J, Park JY, Yi M, Yang S, Kwon MJ, Han SS, Kim BR, Khang CH, Park B, Lim SE, Jung K, Kong S, Karunakaran M, Oh HS, Kim H, Kim S, Park J, Kang S, Choi WB, Kang S, Lee YH: Genome-wide functional analysis of pathogenicity genes in the rice blast fungus. Nat Genet 2007, 39:56I-565.

39. Fusarium Comparative Database [http://www.broad.mit.edu/ annotation/genome/fusarium_group/MultiHome.html]

40. MIPS Munich Information Center for Protein Sequences [http://mips.gsf.de]

41. Wills EA, Roberts IS, Del Poeta M, Rivera J, Casadevall A, Cox GM, Perfect JR: Identification and characterization of the Cryptococcus neoformans phosphomannose isomerase-encoding gene, MANI, and its impact on pathogenicity. Mol Microbiol 2001, 40:610-620.

42. Hilditch S, Berghall S, Kalkkinen N, Penttila M, Richard P: The missing link in the fungal D-galacturonate pathway: identification of the L-threo-3-deoxy-hexulosonate aldolase. I Biol Chem 2007, 282:26195-26201.

43. Bugos RC, Sutherland JB, Adler JH: Phenolic compound utilization by the soft rot fungus Lecythophora hoffmannii. Appl Environ Microbiol 1988, 54: 1882-1885.

44. Harwood CS, Parales RE: The beta-ketoadipate pathway and the biology of self-identity. Annu Rev Microbiol I996, 50:553-590.

45. Martinez AT, Speranza M, Ruiz-Duenas FJ, Ferreira P, Camarero S, Guillen F, Martinez MJ, Gutierrez A, del Rio JC: Biodegradation of lignocellulosics: microbial, chemical, and enzymatic aspects of the fungal attack of lignin. Int Microbiol 2005, 8: I 95-204.

46. Mazur P, Pieken WA, Budihas SR, Williams SE, Wong S, Kozarich JW: Cis,cis-muconate lactonizing enzyme from Trichosporon cutaneum: evidence for a novel class of cycloisomerases in eucaryotes. Biochemistry 1994, 33:1961-1970.

47. Carapito R, Hatsch D, Vorwerk S, Petkovski E, Jeltsch JM, Phalip V: Gene expression in Fusarium graminearum grown on plant cell wall. Fungal Genet Biol 2007, 45:738-748.

48. Kimura A, Takano Y, Furusawa I, Okuno T: Peroxisomal metabolic function is required for appressorium-mediated plant infection by Colletotrichum lagenarium. Plant Cell 200I, 13:1945-1957.

49. Ramos-Pamplona $\mathrm{M}, \mathrm{Naqvi} \mathrm{NI}$ : Host invasion during rice-blast disease requires carnitine-dependent transport of peroxisomal acetyl-CoA. Mol Microbiol 2006, 6 I:61-75.

50. Soustre I, Letourneux Y, Karst F: Characterization of the Saccharomyces cerevisiae RTAI gene involved in 7-aminocholesterol resistance. Curr Genet 1996, 30:121-125.

5I. Giles SS, Batinic-Haberle I, Perfect JR, Cox GM: Cryptococcus neoformans mitochondrial superoxide dismutase: an essential link between antioxidant function and high-temperature growth. Eukaryot Cell 2005, 4:46-54.

52. Narasipura SD, Chaturvedi V, Chaturvedi S: Characterization of Cryptococcus neoformans variety gattii SOD2 reveals distinct roles of the two superoxide dismutases in fungal biology and virulence. Mol Microbiol 2005, 55: 1782-1800

53. Fang GC, Hanau RM, Vaillancourt LJ: The SOD2 gene, encoding a manganese-type superoxide dismutase, is up-regulated during conidiogenesis in the plant-pathogenic fungus Colletotrichum graminicola. Fungal Genet Biol 2002, 36: I55-I65.

54. Hwang CS, Baek YU, Yim HS, Kang SO: Protective roles of mitochondrial manganese-containing superoxide dismutase against various stresses in Candida albicans. Yeast 2003, 20:929-94l.

55. Tanaka A, Shiotani H, Yamamoto M, Tsuge T: Insertional mutagenesis and cloning of the genes required for biosynthesis of the host-specific AK-toxin in the Japanese pear pathotype of Alternaria alternata. Mol Plant Microbe Interact 1999, I 2:691-702.

56. Fang $\mathrm{W}$, Pei $\mathrm{Y}$, Bidochka $\mathrm{MJ}$ : A regulator of a $\mathbf{G}$ protein signalling (RGS) gene, cag8, from the insect-pathogenic fungus Metarhizium anisopliae is involved in conidiation, virulence and hydrophobin synthesis. Microbiology 2007, I 53:1017-1025.

57. Segers GC, Regier JC, Nuss DL: Evidence for a role of the regulator of G-protein signaling protein CPRGS-I in Galpha subunit CPG-I-mediated regulation of fungal virulence, conidiation, and hydrophobin synthesis in the chestnut blight 
fungus Cryphonectria parasitica. Eukaryot Cell 2004, 3: | 454-| 463.

58. Wang P, Cutler J, King J, Palmer D: Mutation of the regulator of G protein signaling CrgI increases virulence in Cryptococcus neoformans. Eukaryot Cell 2004, 3:1028-1035.

59. PHI-base Pathogen Host Interactions [http://www.phibase.org]

60. Kiel JA, Veenhuis $M$, Klei IJ van der: PEX genes in fungal genomes: common, rare or redundant. Traffic 2006, 7:129|-1303.

61. PSORT [http://www.psort.org]

62. SMART Simple Modular Architecture Research Tool [http:/ /smart.embl-heidelberg.de/]

63. McFadden HG, Wilson IW, Chapple RM, Dowd C: Fusarium wilt (Fusarium oxysporum f. sp. vasinfectum) genes expressed during infection of cotton (Gossypium hirsutum). Mol Plant Pathol 2006, 7:87-I0I.

64. Baumlein H, Braun H, Kakhovskaya IA, Shutov AD: Seed storage proteins of spermatophytes share a common ancestor with desiccation proteins of fungi. J Mol Evol 1995, 4I: I070- I075.

65. Alonso JM, Stepanova AN, Leisse TJ, Kim CJ, Chen H, Shinn P, Stevenson DK, Zimmerman J, Barajas P, Cheuk R, Gadrinab C, Heller C, Jeske A, Koesema E, Meyers CC, Parker H, Prednis L, Ansari Y, Choy N, Deen H, Geralt M, Hazari N, Hom E, Karnes M, Mulholland C, Ndubaku R, Schmidt I, Guzman P, Aguilar-Henonin L, Schmid, et al.: Genome-wide insertional mutagenesis of Arabidopsis thaliana. Science 2003, 30 I:653-657.

66. Jeon JS, Lee S, Jung KH, Jun SH, Jeong DH, Lee J, Kim C, Jang S, Yang K, Nam J, An K, Han MJ, Sung RJ, Choi HS, Yu JH, Choi JH, Cho SY, Cha SS, Kim SI, An G: T-DNA insertional mutagenesis for functional genomics in rice. Plant J 2000, 22:56 I-570.

67. Sallaud C, Gay C, Larmande P, Bes M, Piffanelli P, Piegu B, Droc G, Regad F, Bourgeois E, Meynard D, Perin C, Sabau X, Ghesquiere A, Glaszmann JC, Delseny M, Guiderdoni E: High throughput T-DNA insertion mutagenesis in rice: a first step towards in silico reverse genetics. Plant / 2004, 39:450-464.

68. Bundock P, den Dulk-Ras A, Beijersbergen A, Hooykaas PJ: Transkingdom T-DNA transfer from Agrobacterium tumefaciens to Saccharomyces cerevisiae. EMBO J 1995, 14:3206-32।4.

69. de Groot MJ, Bundock P, Hooykaas PJ, Beijersbergen AG: Agrobacterium tumefaciens-mediated transformation of filamentous fungi. Nat Biotechnol 1998, 16:839-842.

70. Idnurm A, Reedy JL, Nussbaum JC, Heitman J: Cryptococcus neoformans virulence gene discovery through insertional mutagenesis. Eukaryot Cell 2004, 3:420-429.

7I. Rogers CW, Challen MP, Green JR, Whipps JM: Use of REMI and Agrobacterium-mediated transformation to identify pathogenicity mutants of the biocontrol fungus, Coniothyrium minitans. FEMS Microbiol Lett 2004, 241:207-2 I4.

72. Choi J, Park J, Jeon J, Chi MH, Goh J, Yoo SY, Jung K, Kim H, Park SY, Rho HS, Kim S, Kim BR, Han SS, Kang S, Lee YH: Genome-wide analysis of T-DNA integration into the chromosomes of Magnaporthe oryzae. Mol Microbiol 2007, 66:37I-382.

73. Forsbach A, Schubert D, Lechtenberg B, Gils M, Schmidt R: A comprehensive characterization of single-copy T-DNA insertions in the Arabidopsis thaliana genome. Plant Mol Biol 2003, 52:161-176.

74. Kim SR, Lee J, Jun SH, Park S, Kang HG, Kwon S, An G: Transgene structures in T-DNA-inserted rice plants. Plant Mol Biol 2003, 52:76I-773.

75. Li G, Zhou Z, Liu G, Zheng F, He C: Characterization of T-DNA insertion patterns in the genome of rice blast fungus Magnaporthe oryzae. Curr Genet 2007, 5 I:233-243.

76. Meng Y, Patel G, Heist M, Betts MF, Tucker SL, Galadima N, Donofrio NM, Brown D, Mitchell TK, Li L, Xu JR, Orbach M, Thon M, Dean RA, Farman ML: A systematic analysis of T-DNA insertion events in Magnaporthe oryzae. Fungal Genet Biol 2007, 44: I050-I 064.

77. Sha Y, Li S, Pei Z, Luo L, Tian Y, He C: Generation and flanking sequence analysis of a rice T-DNA tagged population. Theor Appl Genet 2004, I08:306-3 I4.

78. Walton FJ, Idnurm A, Heitman J: Novel gene functions required for melanization of the human pathogen Cryptococcus neoformans. Mol Microbiol 2005, 57:1381-1396.

79. A grobacterium tumerfaciens-mediated transformation Database for M. oryzae [http://atmt.snu.ac.kr/]

80. Jedd G, Chua NH: A new self-assembled peroxisomal vesicle required for efficient resealing of the plasma membrane. Nat Cell Biol 2000, 2:226-23I.

8I. Soundararajan S, Jedd G, Li X, Ramos-Pamplona M, Chua NH, Naqvi $\mathrm{NI}$ : Woronin body function in Magnaporthe grisea is essential for efficient pathogenesis and for survival during nitrogen starvation stress. Plant Cell 2004, 16:1564-I574.

82. Bosch $\mathrm{H}$ van den, Schutgens RB, Wanders RJ, Tager JM: Biochemistry of peroxisomes. Annu Rev Biochem 1992, 6I:157-197.

83. Holroyd C, Erdmann R: Protein translocation machineries of peroxisomes. FEBS Lett 200I, 50I:6-10.

84. Klose J, Kronstad JW: The multifunctional beta-oxidation enzyme is required for full symptom development by the biotrophic maize pathogen Ustilago maydis. Eukaryot Cell 2006, 5:2047-206I.

85. Wang ZY, Soanes DM, Kershaw MJ, Talbot NJ: Functional analysis of lipid metabolism in Magnaporthe grisea reveals a requirement for peroxisomal fatty acid beta-oxidation during appressorium-mediated plant infection. Mol Plant Microbe Interact 2007, 20:475-491.

86. Tenney K, Hunt I, Sweigard J, Pounder JI, McClain C, Bowman EJ, Bowman $B J$ : Hex-I, a gene unique to filamentous fungi, encodes the major protein of the Woronin body and functions as a plug for septal pores. Fungal Genet Biol 2000, 3I:205-2I7.

87. Weber I, Assmann D, Thines E, Steinberg G: Polar localizing class $V$ myosin chitin synthases are essential during early plant infection in the plant pathogenic fungus Ustilago maydis. Plant Cell 2006, 18:225-242.

88. Werner S, Sugui JA, Steinberg G, Deising HB: A chitin synthase with a myosin-like motor domain is essential for hyphal growth, appressorium differentiation, and pathogenicity of the maize anthracnose fungus Colletotrichum graminicola. Mol Plant Microbe Interact 2007, 20:1555-1567.

89. Kitagaki $\mathrm{H}$, Ito $\mathrm{K}$, Shimoi $\mathrm{H}$ : A temperature-sensitive dcwl mutant of Saccharomyces cerevisiae is cell cycle arrested with small buds which have aberrant cell walls. Eukaryot Cell 2004, 3:1297-I306.

90. Kitagaki $\mathrm{H}, \mathrm{Wu} \mathrm{H}$, Shimoi $\mathrm{H}$, Ito $\mathrm{K}$ : Two homologous genes, DCWI (YKLO46c) and DFG5, are essential for cell growth and encode glycosylphosphatidylinositol (GPI)-anchored membrane proteins required for cell wall biogenesis in Saccharomyces cerevisiae. Mol Microbiol 2002, 46: 101 I- 1022.

91. Papamichos-Chronakis M, Petrakis T, Ktistaki E, Topalidou I, Tzamarias D: Cti6, a PHD domain protein, bridges the Cyc8Tup I corepressor and the SAGA coactivator to overcome repression at GALI. Mol Cell 2002, 9: I297-I 305.

92. Smith RL, Johnson AD: Turning genes off by Ssn6-Tup I: a conserved system of transcriptional repression in eukaryotes. Trends Biochem Sci 2000, 25:325-330.

93. Daniel JA, Grant PA: Multi-tasking on chromatin with the SAGA coactivator complexes. Mutat Res 2007, 6 I 8: I35- I 48.

94. Laprade L, Boyartchuk VL, Dietrich WF, Winston F: Spt3 plays opposite roles in filamentous growth in Saccharomyces cerevisiae and Candida albicans and is required for C. albicans virulence. Genetics 2002, 161:509-519.

95. Hood EE, Gelvin SB, Melchers S, Hoekema A: New Agrobacterium helper plasmids for gene transfer to plants (EHA I05). Trans Res 1993, 2:208-218.

96. Sambrook J, Russel DW: Molecular Cloning: a Laboratory Manual 3rd edition. New York: Cold Spring Harbor Laboratory Press; 200I.

97. Mattanovich D, Ruker F, Machado AC, Laimer M, Regner F, Steinkellner H, Himmler G, Katinger H: Efficient transformation of Agrobacterium spp. by electroporation. Nucleic Acids Res 1989, 17:6747.

98. Covert SF, Kapoor P, Lee M, Briley A, Nairn CJ: Agrobacterium tumefaciens-mediated transformation of Fusarium circinatum. Mycol Res 200I, 105:259-264.

99. Lagopodi AL, Ram AF, Lamers GE, Punt PJ, Hondel CA Van den, Lugtenberg BJ, Bloemberg GV: Novel aspects of tomato root colonization and infection by Fusarium oxysporum f. sp. radicislycopersici revealed by confocal laser scanning microscopic analysis using the green fluorescent protein as a marker. Mol Plant Microbe Interact 2002, 15: 172-179.

100. Houterman PM, Cornelissen BJ, Rep M: Suppression of plant resistance gene-based immunity by a fungal effector. PLoS Pathog 2008, 4: el 00006I.

I0I. Mullins ED, Chen X, Romaine P, Raina r, Geiser DM, Kang S: Agrobacterium-mediated transformation of Fusarium oxysporum: an efficient tool for insertional mutagenesis and gene transfer. Phytopathology 200I, 9I:173-I80.

102. Takken FL, Van Wijk R, Michielse CB, Houterman PM, Ram AF, Cornelissen $B J$ : A one-step method to convert vectors into binary 
vectors suited for Agrobacterium-mediated transformation. Curr Genet 2004, 45:242-248.

103. Wellman FL: A technique for studying host resistance and pathogenicity in tomato Fusarium wilt. Phytopathology 1939, 29:945-956.

104. BLAST Basic Local Alignment and Search Tool [http:// www.ncbi.nlm.nih.gov/BLAST]

105. Kolar M, Punt PJ, Hondel CA van den, Schwab H: Transformation of Penicillium chrysogenum using dominant selection markers and expression of an Escherichia coli lacZ fusion gene. Gene 1988, 62:127-134.

106. Hajdukiewicz P, Svab Z, Maliga P: The small, versatile pPZP family of Agrobacterium binary vectors for plant transformation. Plant Mol Biol 1994, 6:989-994. 